\title{
The Use of Pressurized Eccentric Tubes to Study the Effect of Hydrostatic Stress on Swelling
}

W. G. Wolfer

T. C. Reiley 


\section{DISCLAIMER}

This report was prepared as an account of work sponsored by an agency of the United States Government. Neither the United States Government nor any agency Thereof, nor any of their employees, makes any warranty, express or implied, or assumes any legal liability or responsibility for the accuracy, completeness, or usefulness of any information, apparatus, product, or process disclosed, or represents that its use would not infringe privately owned rights. Reference herein to any specific commercial product, process, or service by trade name, trademark, manufacturer, or otherwise does not necessarily constitute or imply its endorsement, recommendation, or favoring by the United States Government or any agency thereof. The views and opinions of authors expressed herein do not necessarily state or reflect those of the United States Government or any agency thereof. 


\section{DISCLAIMER}

Portions of this document may be illegible in electronic image products. Images are produced from the best available original document. 


\section{Printed in the United States of America. Available from National Technical Information Service \\ U.S. Department of Commerce 5285 Port Royal Road, Springfield, Virginia 22161 \\ Price: Printed Copy $\$ 4.00$; Microfiche $\$ 3.00$}

This report was prepared as an account of work sponsored by the United States Government. Neither the United States nor the Energy Research and Development Administration/United States Nuclear Regulatory Commission, nor any of their employees, nor any of their contractors, subcontractors, or their employees, makes any warranty, express or implied, or assumes any legal liability or responsibility for the accuracy, completeness or usefulness of any information, apparatus, product or process disclosed, or represents that its use would not infringe privately owned rights. 

operated by UNION CARBIIDE CORPORATION for the

ENERGY RESEARCH AND DEVELOPMENT ADMINISTRATION

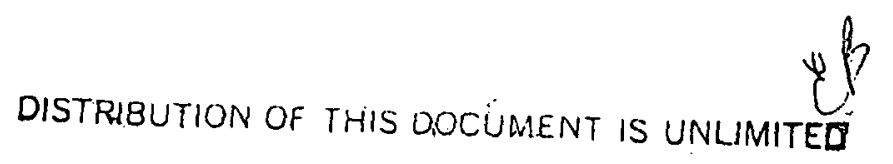




\section{THIS PAGE}

WAS INTENTIONALLY LEFT BLANK 


\section{CONTENTS}

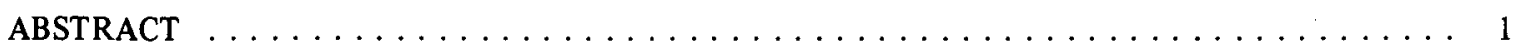

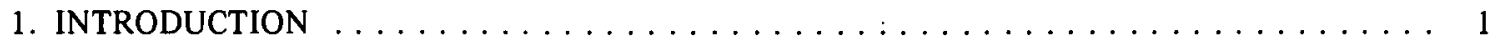

2. A CONSTITUTIVE EQUATION FOR RADIATION-INDUCED DEFORMATION $\ldots \ldots \ldots 2$

3. THE THIN-WALLED TUBE WITH NONUNIFORM WALL THICKNESS $\ldots \ldots \ldots \ldots \ldots$

4. THE THICK-WALLED ECCENTRIC TUBE $\ldots \ldots \ldots \ldots \ldots \ldots$

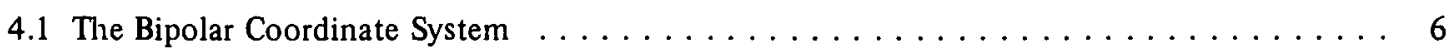

4.2 The Elastic Deformation Accompanying Pressurization $\ldots \ldots \ldots \ldots$

5. APPIICATION OF THE CONSTITUTIVE LAW TO THE PLASTIC DEFORMATION OF PRESSURIZED ECCENTRIC TUBES $\ldots \ldots \ldots \ldots \ldots \ldots \ldots \ldots$

5.1 Plastic Analysis ... . . . . . . . . . . . . . . . . . . . . . 14

5.2 Point of Maximum Shear Stress $\ldots \ldots \ldots \ldots \ldots \ldots \ldots$

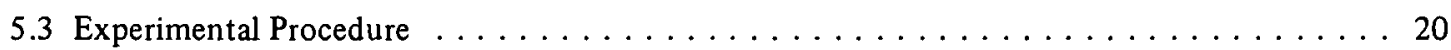

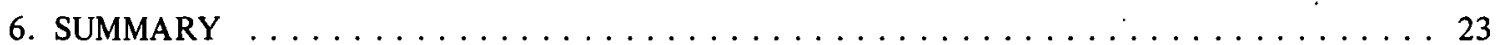




\title{
THE USE OF PRESSURIZED ECCENTRIC TUBES TO STUDY THE EFFECT OF HYDROSTATIC STRESS ON SWELLING
}

\author{
W. G. Wolfer ${ }^{1}$ and T. C. Reiley
}

\begin{abstract}
A technique for measuring the effect of hydrostatic stress on radiation-induced swelling is presented. This technique is based on the nonuniform hydrostatic stress that arises when an eccentric tube (a tube with inner and outer surfaces having dissimilar centers of revolution) is internally pressurized. The elastic analyses of the thin- and thick-walled eccentric tube are given. The elastic stress state is allowed to relax plastically, based on a constitutive law for deformation during neutron irradiation. In this case, the constitutive law contains a linearly stress-dependent deviatoric strain rate and a dilatation rate that is linearly dependent on hydrostatic stress. Emphasis is placed on the specimen design and experimental procedure for in-reactor experiments in which the coefficient relating hydrostatic stress and swelling is sought. It is shown that, for the $316 \mathrm{~L}$ stainless steel specimens placed in EBR-II, we may expect that any appreciable effect of hydrostatic stress on swelling will be observable through changes in specimen curvature.
\end{abstract}

\section{INTRODUCTION}

During the plastic deformation of metals, the volume or density normally remains constant. Important exceptions may be noted during the tertiary stage of thermal creep, during ductile fracture processes in general, and during deformation under fast-neutron irradiation conditions that cause swelling. Once internal cracks or cavities are formed, the application of stress along with associated plastic deformation may contribute to the growth of these defects, which leads to a decrease in specimen density. The general relationship between applied stress and plastic strain is described herein for the situation in which plastic strain is not volume conserving; that is, a constitutive law is developed for the case where dilatation accompanies deformation.

The primary emphasis is on a simple device, a pressurized eccentric tube, that may allow highly accurate measurement of the effect of stress on volume changes during plastic deformation. This device is particularly suited for in-reartor deformations, and we shall henceforth çonçern ourselves only with its application for radiation-induced creep and swelling during fast-neutron irradiation. However, the device is also applicable for studying other deformation processes for which volume is not conserved.

A form of the constitutive law for radiation-induced deformation is discussed in Sect. 2; in Sect. 3 we present the elastic analysis of the pressurized eccentric thin-walled tube. The more elaborate and rigorous stress analysis for the thick-walled tube is given in Sect. 4. (The reader not interested in analytical details may skip this section.) The final equations used for the experimental determination of stress-induced volume changes along with the actual specimen design requirements are given in Sect. 5 .

\section{A CONSTITUTIVE EOUATION FOR RADIATION-INDUCED DEFORMATION}

A constitutive equation for radiation-induced deformation can be derived from microscopic models based on the climb and gide of dislocations, in association with the growth of voids. Such a derivation is given in ref. 2 , where it is shown that the constitutive relation depends on microscopic parameters that

1. Now at Department of Nuclear Engineering, University of Wisconsin.

2. W. G. Wolfer, M. Ashkin, and A. Boltax, Properties of Reactor Structural Alloys After Neutron or Particle Irradiation, ASTM STP 570, ASTM (197.5) pp. 233-258. 
describe the dislocation structure; however, such an approach will not be taken here. It is possible to develop the constitutive relation based on mathematical reasoning and empirical macroscopic information without recourse to microscopic models.

We assume that the strain rate tensor $\dot{\epsilon}$ (or $\dot{\epsilon}_{i j}$ ) is a function of the stress tensor $\sigma$ and the accumulated strain $\epsilon$. Furthermore, $\dot{\epsilon}$ may also be a function of the neutron flux, $\phi$ the time, $t$, and the temperature, $T$. Our assumption implies that

$$
\dot{\epsilon}=\dot{\epsilon}(u, \dot{\epsilon}, \phi, t, T) \text {. }
$$

It is always possible (at least for small strains) to decompose the tensor quantities into their isotropic and deviatoric components; that is,

$$
\begin{aligned}
& \epsilon=(1 / 3) \Delta 1+e, \\
& \sigma=\sigma_{H} 1+s,
\end{aligned}
$$

where 1 is the Kronecker tensor $\left(\delta_{i i}\right), \Delta$ is the volume dilation, ${ }^{\prime} \sigma_{H}$ is the hydrostatic stress, and $e$ and $s$ are the deviatoric strain and stress respectively.

Based on the work of Rivlin ${ }^{3}$ and Wineman and Pipkin, ${ }^{4}$ the constitutive equation for an isotropic material can be shown to be of the form

$$
\dot{\Delta}=f_{0}
$$

for the rate of dilatation, and

$$
\dot{e}=f_{1} e+f_{2} s+f_{3} e^{2}+f_{4} s^{2}+f_{5}(e s+s e)+f_{6}\left(e s^{2}+s^{2} e\right)+f_{7}\left(e^{2} s+s e^{2}\right)+f_{8}\left(e^{2} s^{2}+s^{2} e^{2}\right)
$$

for the rate of deviatoric strain, where the functions $f_{0}$ through $f_{8}$ are functions of $\phi, t, T$, and the ten invariants

$$
\sigma_{H}, \operatorname{tr}\left(s^{2}\right), \operatorname{det}(s), \Delta, \operatorname{tr}\left(e^{2}\right), \operatorname{det}(e), \operatorname{tr}(s e), \operatorname{tr}\left(e^{2} s\right), \operatorname{tr}\left(s^{2} e\right), \operatorname{tr}\left(e^{2} s^{2}\right) .
$$

Here the tensor product is defined as

$$
\boldsymbol{P} \cdot \mathrm{s}=\Gamma_{1} / k \rho_{i k} s_{k j j}
$$

tr is the sum of the diagonal elements of the tensor, and det is the determinant of the tensor matrix. Since tr $\dot{e} \equiv O$, the following relationship must be satisfied by the functions $f_{3}$ through $f_{8}$ :

$$
f_{3} \operatorname{tr}\left(e^{2}\right)+f_{4} \operatorname{tr}\left(s^{2}\right)+2 f_{5} \operatorname{tr}(s e)+2 f_{6} \operatorname{tr}\left(s^{2} e\right)+2 f_{7} \operatorname{tr}\left(s e^{2}\right)+2 f_{8} \operatorname{tr}\left(s^{2} e^{2}\right)=0 .
$$

Equations (4), (5), and (7) form the most general constitutive law for isotropic materials when written in the form of Eq. (1). To further simplify these equations, one must use experimental information.

3. R. S. Rivlin, J. Ration. Mech. Anal. 4, 681-702 (1955).

4. A. S. Wineman and A. S. Pipkin, Arch. Ration. Mech. Anal. 17, 184-214 (1964). 
First a major simplification of our constitutive law may be obtained by assuming that the previous deviatoric deformation has no effect on the present deformation rate. This is consistent with the limited observations on in-reactor deformation. It is a reasonable assumption, given the small deviatoric strains imposed on reactor components during irradiation, even though they may be accompanied by large dilatational strains. (This is tantamount to the assumption that the small in-reactor deformation rate is governed by a radiation-controlled microstructure rather than a deviatoric strain-controlled microstructure.) Hence, $\dot{e}$ and $\dot{\Delta}$ are independent of $e$, but not necessarily of $\Delta$, and

$$
f_{1}=f_{3}=f_{5}=f_{6}=f_{7}=f_{8}=0 \text {. }
$$

Then, because of Eq. (7), we must also conclude that $f_{4}=0$. It follows that the nonvanishing terms $f_{0}$ and $f_{2}$ depend only on the lower order invariants $\sigma_{H}, \operatorname{tr}\left(s^{2}\right)$, det $(s)$, and $\Delta$. Furthermore, since only linear stress dependence of the deformation rate is normally observed, we will ignore the dependence of $f_{0}$ and $f_{2}$ on the invariants $\operatorname{tr}\left(s^{2}\right)$ and $\operatorname{det}(s)$. Thus, the constitutive equations become:

$$
\dot{\Delta}=f_{0}
$$

and

$$
\dot{e}=f_{2} s \text {, }
$$

where

$$
f_{i}=f_{i}\left(\phi, t, T, \sigma_{H}, \Delta\right)
$$

A similar line of reasoning may be applied to the situation in which large deviatoric strains are imposed on reactor components, e.g., cold-working during their manufacture, preceding placement in reactors. We can deal with this case by treating $e$ as the strains associated with cold-working, letting $e=e_{p}$. If the material is exposed to radiation under no external stress, then Eq. (5) gives:

$$
\dot{e}^{\prime}=f_{1} e_{p}+f_{3} e_{p}^{2}
$$

and describes radiation-induced shape changes without external loads. And, together with the equation $\dot{\Delta}=$ $f_{0}$, these are the constilutive equations for anisotropic growth.

\section{THE THIN-WALLED TUBE WITH NONUNIFORM WALL THICKNESS}

In this section the description of the elastic strains and curvature will be given for a pressurized eccentric thin-walled tube. This treatment will be modified later in Sect. 5 to allow discussion of the plastic deformation of the tube in light of the previously developed constitutive equations.

For a thin-walled tube under an internal pressure $p_{0}$, the average stresses in the radial $(r)$; circumferential $(\theta)$, and axial $(z)$ directions are given approximately by ${ }^{5}$

$$
\dot{\bar{\sigma}}_{r r}=-p_{0} / 2, \bar{\sigma}_{\theta \theta}=p_{0} r / \gamma, \bar{\sigma}_{z z}=p_{0} r / 2 \gamma
$$

5. See, for example D. C. Drucker, Introduction to Mechanics of Deformable Solids, p. 78, McGraw-Hill, New York, 1967. 
where $r$ is the tube radius and $\gamma$ is the wall thickness. If $r / \gamma \gg 1$, as it must be for the above approximations to hold, then $\bar{\sigma}_{r r}$ is much less than $\bar{\sigma}_{\theta \theta}$ or $\bar{\sigma}_{z z}$. For these conditions the elastic strains in the tube in the radial, circumferential, and axial directions are given by

$$
\begin{aligned}
& \epsilon_{r r}=-\frac{3 v}{E} \frac{p_{0} r}{2 \gamma}, \\
& \epsilon_{\theta \theta}=\frac{2-\nu}{E} \frac{p_{0} r}{2 \gamma}, \\
& \epsilon_{z z}=\frac{1-2 v p_{0} r}{E} \frac{2 \gamma}{2} ;
\end{aligned}
$$

where $E$ is Young's modulus and $\nu$ is Poisson's ratio. One point to be noted is that if $\nu=1 / 2$, as it would be for an incompressible medium or for plastic deformation, $\epsilon_{z z}=0$, and no axial elongation would take place. For $\nu<1 / 2$, an axial expansion would occur with a magnitude inversely proportional to the wall thickness, $\gamma$.

One may include the effect of a variation in wall thickness on the above expressions. For an eccentric tube, as shown in Fig. 1, let the wall thickness change along the circumference as:

$$
\gamma(\theta)=\gamma_{0}+\delta \gamma \cos \theta
$$

The cylinder expands axially more on the thinner side than on the thicker, which leads to bending of the tube. We can compute this bending in terms of a radius of curvature, $R$ from simple geometric relations (see Fig. 1). If $L$ is the original tube length, let the length on the thinner side (AA) be $L\left(1+\epsilon_{z z}{ }^{+}\right)$and on the

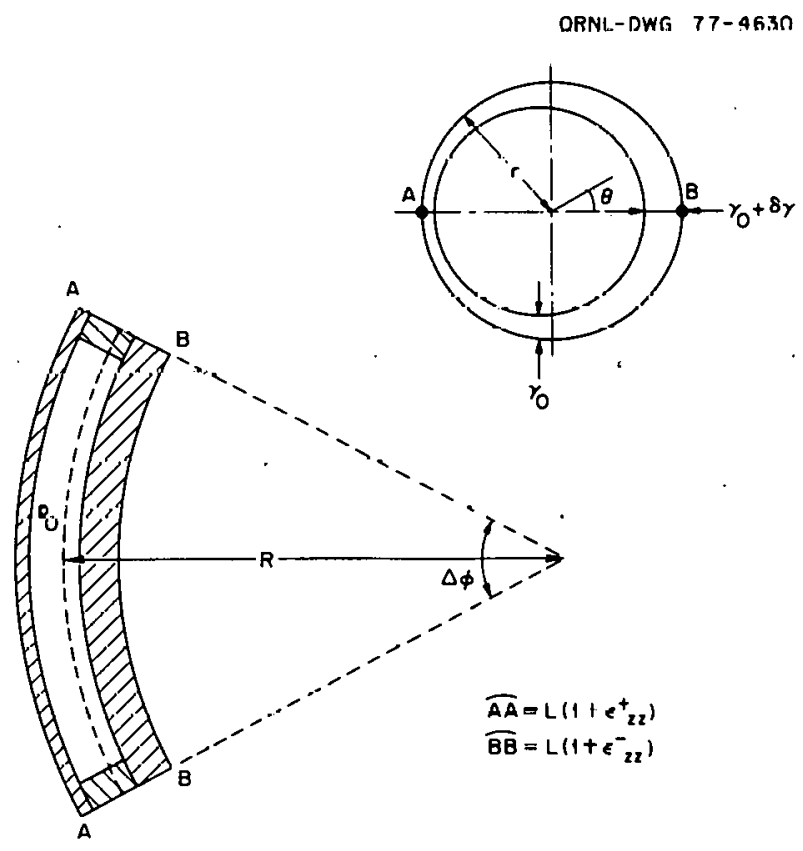

Fig. 1. The eccentric thin-walled tube under internal pressure. 
thicker side (BB) be $L\left(1+\epsilon_{z z}-\right)$, where $\epsilon_{z z}{ }^{+}$and $\epsilon_{z z}-$ are the axial strains on the thinner and thicker sides. From Fig. 1, it can be seen that:

$$
\begin{aligned}
& L\left(1+\epsilon_{z z}{ }^{+}\right)=(R+r) \Delta \phi, \\
& L\left(1+\epsilon_{z z^{-}}{ }^{-}\right)=(R-r) \Delta \phi,
\end{aligned}
$$

and

$$
\frac{r}{R}=\frac{\epsilon_{z z^{+}-\epsilon_{z z^{-}}}}{2+\epsilon_{z z^{+}+\epsilon_{z z^{-}}}} \approx \frac{1}{2}\left(\epsilon_{z z^{+}}{ }^{+}-\epsilon_{z z^{-}}{ }^{-}\right) .
$$

Using Eq. (15) and substituting the maximum and minimum values of $\gamma$ for the thicker and thinner sides of the tube, respectively, we find

$$
\frac{r}{R}=(1-2 \dot{\nu}) \frac{p_{0}}{E} \frac{r}{4 \gamma_{0}}\left[\left(1-\frac{\delta \gamma}{\gamma_{0}}\right)^{-1}-\left(1+\frac{\delta \gamma}{\gamma_{0}}\right)^{-1}\right]
$$

For small eccentricities, such that $\delta \gamma \ll \gamma_{0}$, we obtain finally:

$$
\frac{1}{R}=(1-2 \nu) \frac{p_{0}}{E} \frac{\delta \gamma}{2 \gamma_{0}^{2}}
$$

In the next section a similar formula will be developed for the more complicated thick-walled tube having significant eccentricity.

\section{THE THICK-WALLED ECCENTRIC TUBE}

The elastic stress analysis of the eccentric tube has been carried out by several researchers. Using bipolar coordinates, G. B. Jeffery first obtained an exact solution of the stress distribution in an eccentric pipe. ${ }^{6}$ A detailed investigation of the location of the maximum stress was later indertaken by Coker and Filon. ${ }^{7}$ The solution may also be found in a paper by Weinel, ${ }^{8}$ which was then used by Wuest ${ }^{3}$ to evaluate the elastic bending of an internally pressurized eccentric tube. In this section we summarize the results of the above papers that are pertinent to the present problem.

The complete elastic analysis is most conveniently approached by superposing two states of stress. The first state is one of plane strain (i.e., no axial strains are allowed) in which the eccentric tube is pressurized but is constrained to remain straight through the application of end tractions, $M_{0}$ and $T_{0}$, at the centroid (Fig. 2). The second state of stress is that arising from the application of the opposite end tractions, $-M_{0}$ and $-T_{0}$, only. The detailed stress analysis is required for the calculation of the maximum shear stress such

6. G. B. Jeffery, Phil. Trans. Roy Soc. London, .A221, 265-293 (1920).

7. E. G. Coker and L. N. G. Filon, $A$ Treatise on Photo-Elasticity, 2d ed., p. 306, Cambridge University Press, Cambridge, Mass., 1957.

8. E. Weinel, Z. Angew. Math. Mech. 17, 276-287 (1937).

9. W. Wuest, Ing. Arch. 19, 12-21 (1951). 


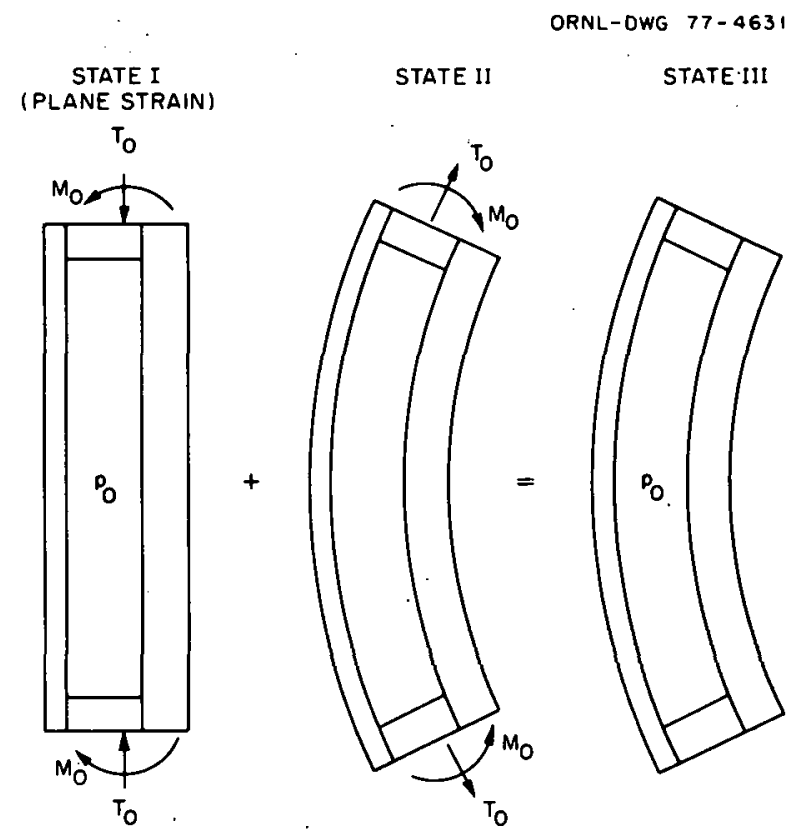

Fig. 2. The superposition of elastic states for a free-standing pressurized eccentric tube.

that, under pressurization, yielding will not occur at any point in the tube. Also, a complete understanding of the stress state is required where the rate of deformation has a nonlinear stress dependence.

\subsection{The Bipolar Coordinate System}

The relation between Cartesian $(x, y)$ and bipolar $(\xi, \eta)$ coordinates is given by:

$$
x=a \frac{\sinh \xi}{\cosh \xi \cos \eta}
$$

and

$$
y=a \frac{-\sin \eta}{\cosh \xi-\cos \eta}
$$

where $a$ is the distance of the pole from the origin, as shown in Fig. 3. The coordinate lines corresponding to $\xi=$ const. represent a family of circles,

$$
(x-a \operatorname{coth} \xi)^{2}+y^{2}=a^{2} / \sinh ^{2} \xi,
$$

and the coordinate lines corresponding to $\eta=$ const. represent another family of circles,

$$
x^{2}+(y-a \cot \eta)^{2}=a^{2} / \sin ^{2} \eta
$$

Thus the cross section of the eccentric tube can be specified by two positive values of $\xi_{\text {, say }} \xi_{1}$ and $\xi_{2}$. If the radii of the circles forming the eccentric annulus are $r_{1}$ (inner) and $r_{2}$ (outer), as shown in Fig. 4 , then, 


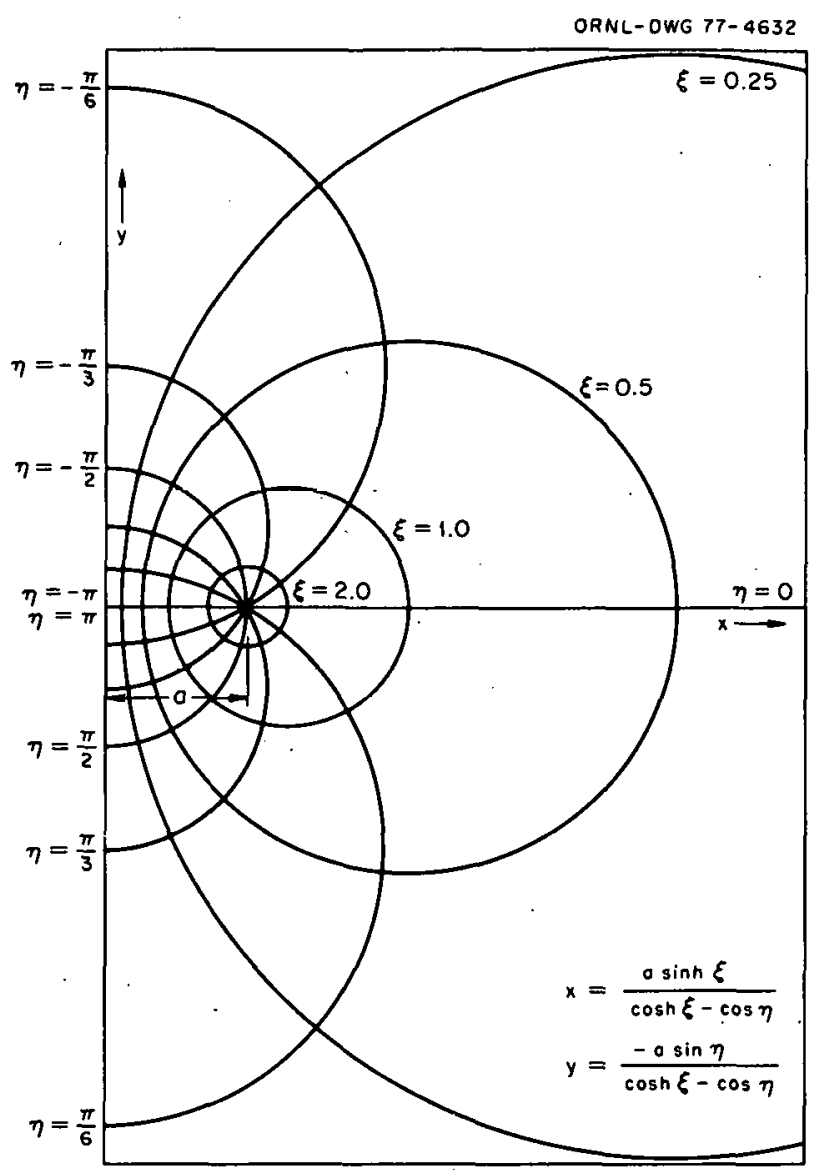

Fig. 3. The bipolar coordinate system.

according to Eq. (21),

$$
r_{1}-a / \sinh \zeta_{1}, \quad r_{2}-a / \text { oinh } \xi_{2}
$$

The centers of these circles are located at $x_{1}=a \operatorname{coth} \xi_{1}$ and $x_{2}=a \operatorname{coth} \xi_{2}$, where the distance between the centers is given by:

$$
b=a\left(\operatorname{coth} \xi_{2}-\operatorname{coth} \xi_{1}\right)=\left(r_{2}^{2}+a^{2}\right)^{1 / 2}-\left(r_{1}^{2}+a^{2}\right)^{1 / 2} .
$$

For a given choice of $r_{2}, r_{1}$, and $b$, the value of $a$ (the polar quantity) is determined and is given by:

$$
a=\frac{1}{2 b}\left[\left(r_{2}^{2}-r_{1}^{2}\right)^{2}-2 b^{2}\left(\dot{r}_{2}^{2}+{r_{1}}^{2}\right)+b^{4}\right]^{1 / 2}
$$

\section{2 'The Elastic Deformation Accompanying Pressurization}

In this section the two states of stress shown in Fig. 2 will be examined. The first state, being one of plane strain, is analyzed using Airy's stress function $\psi(x, y)$, which satisfies the biharmonic equation:

$$
\nabla^{4} \downarrow=0
$$




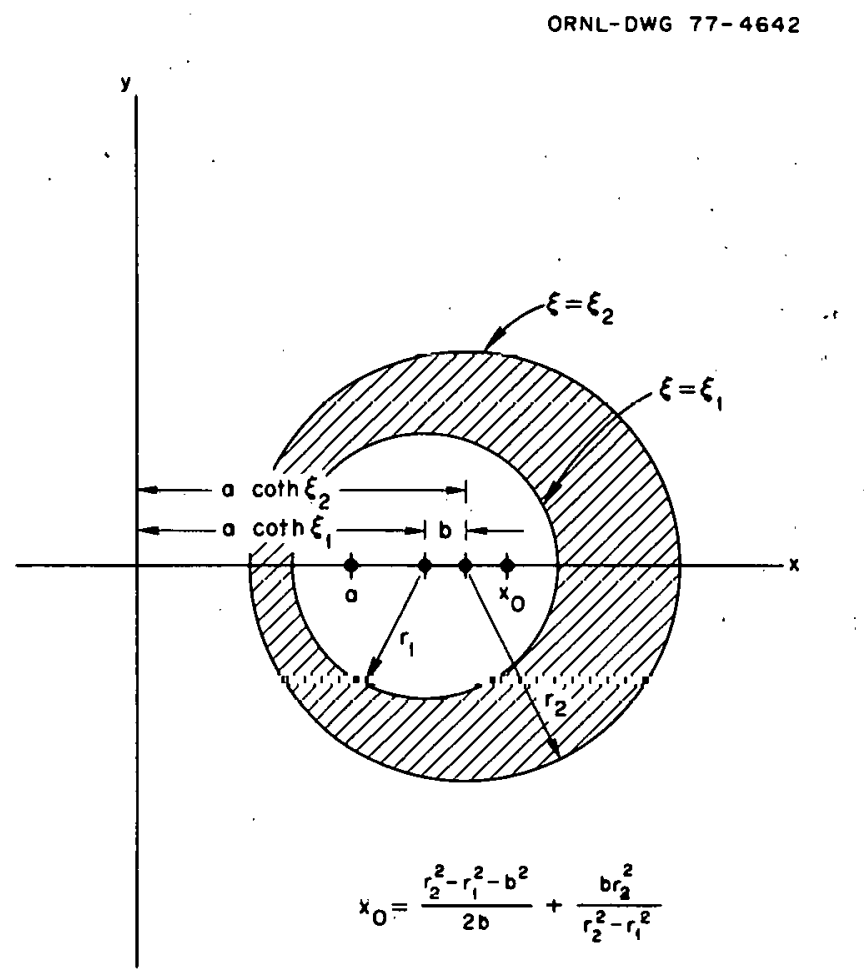

Fig. 4. Dimensional relations for the eccentric tube cross section.

In bipolar coordinates this equation is written as:

$$
\nabla .^{4} \psi=g \quad 3\left[\frac{\partial^{4}}{\partial \xi^{4}}+2 \frac{\partial^{4}}{\partial \xi^{2} \partial \eta^{2}}+\frac{\partial^{4}}{\partial \eta^{4}}=2 \frac{\partial^{2}}{\partial \xi^{2}}+2 \frac{\partial^{2}}{\partial \eta^{2}}+1\right]\left(\frac{\psi}{g}\right),
$$

where.

$$
g=a /(\text { outh } \xi \quad \text { cot } \eta) \text {. }
$$

The stresses are given by the equations:

$$
\begin{aligned}
& \sigma_{\zeta \zeta}=a \quad i\left[\frac{a}{g} \frac{\partial^{2}}{\partial \eta^{2}}-\sinh \xi \frac{\partial}{\partial \xi}-\sin \eta \frac{\partial}{\partial \eta}+\cosh \xi\right]\left(\frac{\psi}{g}\right), \\
& \sigma_{\eta \eta}=a^{-1}\left[\frac{a}{g} \frac{\partial^{2}}{\partial \xi^{2}}-\sinh \xi \frac{\partial}{\partial \xi}-\sin \eta \frac{\partial}{\partial \eta}+\cos \eta\right]\left(\frac{\psi}{g}\right), \\
& \sigma_{\xi \eta}=-\frac{1}{\dot{g}} \frac{\partial^{2}}{\partial \xi \partial \eta}\left(\frac{\psi}{g}\right) .
\end{aligned}
$$

Since the stress distribution is symmetric with respect to the $x$ axis (see Fig. 3), we need a solution of the biharmonic equation that is even and simply periodic in $\eta$. Such a solution is given by: ${ }^{6}$

$$
\psi / g=A \cosh \xi+B(\cosh \xi-\cos \eta)+C \sinh \xi+(G \cosh 2 \xi+H \sinh 2 \xi+F) \cos \eta
$$


where $A$ through $F$ are constants. Inserting this solution into Eqs. (31) to (33), one finds that the $C$ term results in zero stress and can therefore be omitted. Furthermore, we may write

$$
A \cosh \xi+F \cos \eta=A(\cosh \xi-\cos \eta)+(A+F) \cos \eta,
$$

with the result that the first term again leads to zero stress, whereas the second term. is simply a redefinition of the constant $F$. Thus, the $A$ term may be dropped. The remaining constants, $B, F, G$, and $H$, are now determined from the four boundary conditions:

$$
\begin{array}{ll}
\sigma_{\xi \xi}=-p_{0} & \left(\xi=\xi_{1}\right) \\
\sigma_{\xi \xi}=0 & \left(\xi=\xi_{2}\right) \\
\sigma_{\eta \xi}=0 & \left(\xi=\xi_{1}\right) \\
\sigma_{\eta \xi}=0 & \left(\xi=\xi_{2}\right) .
\end{array}
$$

One obtains the four equations:

$$
\begin{aligned}
& -B \sinh \xi_{1} \cosh \xi_{1}+G \cosh 2 \xi_{1}+H \sinh 2 \xi_{1}+F=-a p_{0} \\
& -B \sinh \xi_{2} \cosh \xi_{2}+G \cosh 2 \xi_{2}+H \sinh 2 \xi_{2}+F=0 \\
& -B+2 G \sinh 2 \xi_{1}+2 H \cosh 2 \xi_{1}=0 \\
& -B+2 G \sinh 2 \xi_{2}+2 H \cosh 2 \xi_{2}=0
\end{aligned}
$$

with the following solutions:

$$
\begin{aligned}
& B=2 a N \cosh \left(\xi_{1}-\xi_{2}\right), \\
& F=a N\left[\sinh \left(\xi_{1}-\xi_{2}\right)+\sinh 2 \xi_{2} \cosh \left(\xi_{1}-\xi_{2}\right)\right], \\
& G=-a N \sinh \left(\xi_{1}+\xi_{2}\right), \\
& H=a N \cosh \left(\xi_{1}+\xi_{2}\right),
\end{aligned}
$$

where

$$
N-\frac{1}{2} p_{0}\left[\sinh \left(\xi_{1} \cdot \xi_{2}\right)\left(\sinh ^{2} \xi_{1}+\sinh ^{2} \xi_{2}\right)\right]^{-1}
$$

The stresses can be expressed more conveniently in the following form:

$$
\begin{aligned}
a\left(\sigma_{\eta \eta}+\sigma_{\xi \xi}\right)=2 F+2 G & (2 \cos \eta \cosh \xi-\cos 2 \eta \cosh 2 \xi) \\
& +4 H \sinh \xi\left(\cosh \xi+2 \cosh ^{2} \xi \cos \eta+\cos \eta-4 \cosh \xi \cos ^{2} \eta\right)
\end{aligned}
$$




$$
\begin{aligned}
& a\left(\sigma_{\eta \dot{\eta}}-\sigma_{\xi \xi}\right)=2(\cosh \xi-\cos \eta)(B \sinh \xi+2 G \cos \eta \cdot \cosh 2 \xi+2 H \cos \eta \sinh 2 \xi), \\
& a \sigma_{\eta \xi}=\sin \eta(\cosh \xi-\cos \eta)(-B+2 G \sinh 2 \xi+2 H \cosh 2 \xi) .
\end{aligned}
$$

However, for the numerical evaluation it is better to write these expressions in terms of the dimensionless parameters

$$
\begin{aligned}
& \beta=b /\left(r_{2}-r_{1}\right), \\
& \lambda_{0}=r_{1} / r_{2},
\end{aligned}
$$

and

$$
\lambda=\frac{r}{r_{2}}=\frac{1}{r_{2}}\left(\frac{a}{(\sinh \xi)}\right)=\frac{a}{\sinh \xi}
$$

where

$$
a=\frac{a}{r_{2}}=\frac{1}{2 \beta}\left[\left(1+\lambda_{0}\right)^{2}-2 \beta^{2}\left(1+\lambda_{0}^{2}\right)+\beta^{4}\left(1-\lambda_{0}{ }^{2}\right)\right]^{1 / 2}:
$$

Another parameter, $\chi$, which locates the center of the circle for a given value of $\xi$, is used here also:

$$
\chi(\xi)=\alpha \operatorname{coth} \xi
$$

and

$$
\begin{aligned}
& \chi_{1}=\chi\left(\xi_{1}\right)=\frac{1}{2 \beta}\left[1+\lambda_{0}, \beta^{2}\left(1-\lambda_{0}\right)\right], \\
& \chi_{2}=\chi\left(\xi_{2}\right)=\frac{1}{2 \beta}\left[1+\lambda_{0}+\beta^{2}\left(1-\lambda_{0}\right)\right] .
\end{aligned}
$$

Using Eqs. (34) through (38) and replacing $\sinh \xi$ and $\cosh \xi$ by $\alpha / \lambda$ and $\chi / \lambda$, respectively, we obtain

$$
\begin{aligned}
& \left(\sigma_{\eta \eta}+\sigma_{\xi \xi}\right) \lambda_{0} /(2 \alpha N)=\chi_{1}-\chi_{2}-2 \chi_{2}\left(\chi_{1} \chi_{2}-\alpha^{2}\right)+2 \cos \eta \lambda^{-1}\left[\chi\left(\chi_{1}+\chi_{2}\right)-\chi_{1} \chi_{2}-\alpha^{2}\right] \\
& +\cos 2 \eta \lambda^{-2}\left[2 \chi\left(\chi_{1} \chi_{2}+\alpha^{2}\right)-\left(\chi_{1}+\chi_{2}\right)\left(\chi^{2}+\alpha^{2}\right)\right], \\
& \left(\sigma_{\eta \eta}-\sigma_{\xi \xi}\right) \lambda_{0} /(4 \alpha N)=(\chi / \lambda-\cos \eta)\left\{\lambda^{=1}\left(\chi_{1} \chi_{2}-\alpha^{2}\right)\right. \\
& \left.+\cos \eta \lambda^{-2}\left[2 \chi\left(\chi_{1} \chi_{2}+\alpha^{2}\right)-\left(\chi_{1}+\chi_{2}\right)\left(x^{2}+\alpha^{2}\right)\right]\right\} \\
& \sigma_{i \eta \xi} \lambda_{0} /(4 \alpha N)=\sin \eta(\chi / \lambda-\operatorname{sens} \eta) \lambda^{-2}\left(\chi-\chi_{1}\right)\left(\chi-\chi_{2}\right)
\end{aligned}
$$

where

$$
2 \alpha N / \lambda_{0}=-p_{0} \lambda_{0}{ }^{2} /\left[\alpha^{2} \beta\left(1-\lambda_{0}\right)\left(1+\lambda_{0}^{2}\right)\right]
$$


To illustrate the magnitude of these stresses over the cross section, a perspective view is chosen, as shown in Fig. 5, in which half the cross section of the eccentric tube is mapped onto a rectangular area. In Figs. 6-8 the values of the stresses $\sigma_{\xi \xi}, \sigma_{\eta \eta}$, and $\sigma_{\eta \xi}$ are given for an eccentric tube with the geometric parameters $\lambda_{0}$ and $\beta$ set equal to 0.5 . The vertical axis in the figures is marked in units of $p_{0}$, the internal pressure.

To obtain the value of $\sigma_{z z}$, the axial stress for the unconstrained pressurized eccentric tube, one must add the values of $\sigma_{z z}{ }^{\mathrm{I}}$ and $\sigma_{z z}{ }^{\mathrm{II}}$; as mentioned earlier (see Fig. 2). The value of $\sigma_{z z}{ }^{\mathrm{I}}$ is given by

$$
\sigma_{z z}^{I}=\nu\left(\sigma_{\eta \eta}+\sigma_{\xi \xi}\right)
$$

since we have plane strain conditions. To find $\sigma_{z z}{ }^{\mathrm{II}}$ we must evaluate $T_{0}$, the end traction applied to the tube end caps $\left(+T_{0}\right.$ for state $\mathrm{I},-T_{0}$ for state II). Mechanical equilibrium is the criterion used to evaluate $T_{0}$, as given in Eq. (54):

$$
T_{0}=\pi r_{1}^{2} p_{0}-\iint \sigma_{z z}{ }^{\mathrm{I}} d A
$$

where $\iint d A$ denotes integration over the cross section of the tube. Since

$$
\iint\left(\sigma_{\eta \eta}+\sigma_{\xi \xi}\right) d A=2 \pi r_{1}^{2} p_{0}
$$

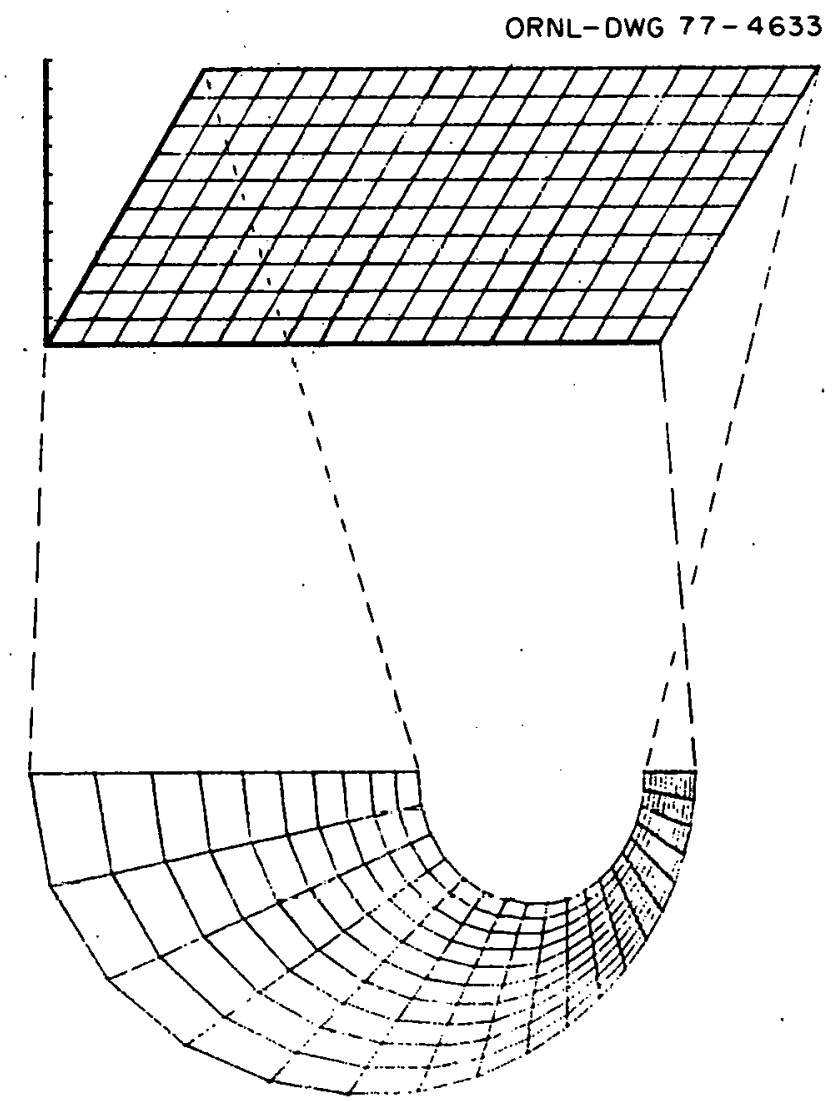

Fig. 5. The mapping used to show the stress distribution over the cross section of the eçentric tube. 


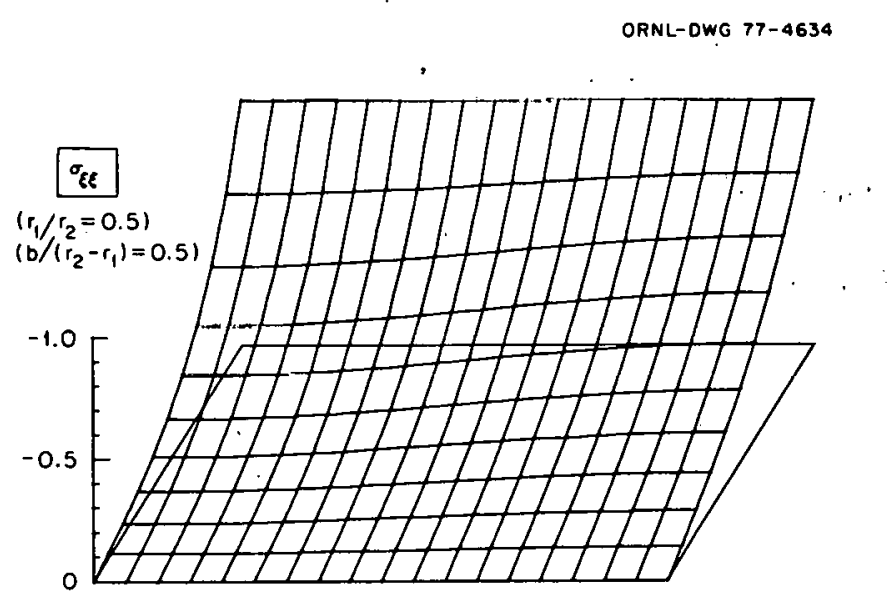

Fig. 6. The value of $v_{\xi \xi}$ uver the eccentric lubic crós section. In units of $p_{0}$, tho intornal proboura.

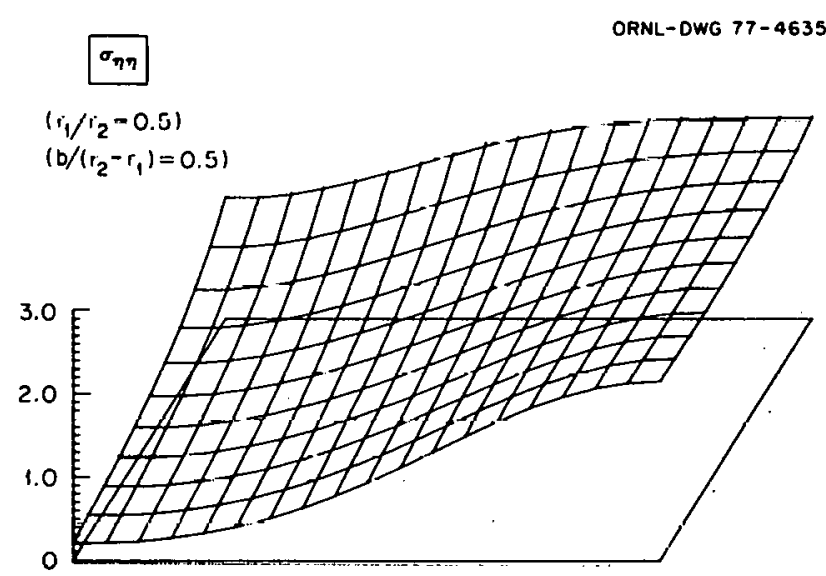

Fig. 7. The value of $a_{\eta \eta}$ over the cccentric tube cross section. In units of $p_{0}$, the internal pressure.

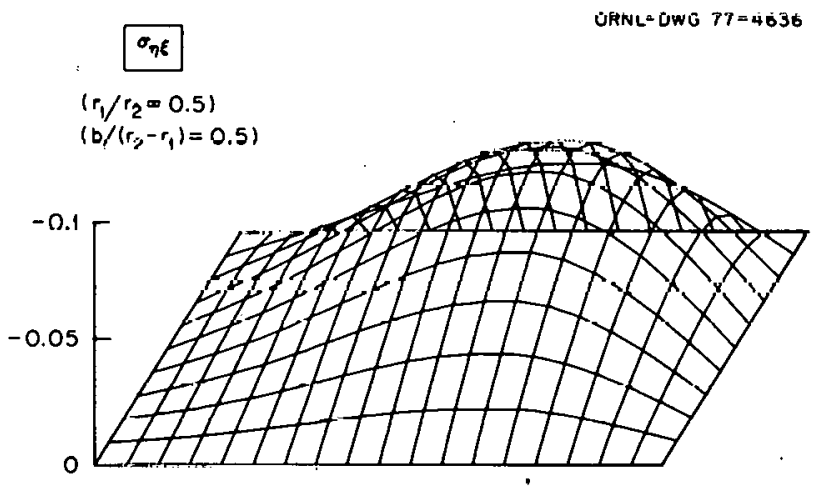

Fig. 8. The value of $\sigma_{\eta \xi}$ over the eccentric tube cross section. In units of $p_{0}$, the internal pressure. 
$T_{0}$ is given by

$$
T_{0}=(1-2 v) \pi r_{1}^{2} p_{0}
$$

The moment $M_{0}$ is found to be

$$
M_{0}=\frac{(1-2 \nu) \pi r_{1}^{2} r_{2}^{2} b p_{0}}{r_{2}^{2}-r_{1}^{2}}
$$

Thus the stress $\sigma_{z z}{ }^{I I}$, arising from the application of $-T_{0}$ and $-M_{0}$ to an unpressurized tube, is

$$
\sigma_{z z}{ }^{\mathrm{II}}=\frac{-M_{0}}{I}\left(x-x_{0}\right)
$$

where $I$ is the moment of incrtia for bending about the $y$ axis,

$$
I=\pi\left(\frac{r_{2}^{4}-r_{1}^{4}}{4}-\frac{b^{2} r_{1}^{2} r_{2}^{2}}{r_{2}{ }^{2}-r_{1}{ }^{2}}\right)
$$

and $x_{0}$ denotes the position of the centroid along the $x$ axis (see Fig. 4) and is given by

$$
x_{0}=\frac{r_{2}^{2}-r_{1}^{2}-b^{2}}{2 b}+\frac{b r_{2}^{2}}{r_{2}^{2}-r_{1}^{2}}
$$

Substituting Eqs. (57), (59), and (60) into Eq. (58),

$$
\sigma_{z z} \mathrm{II}=\frac{-4(1-2 v) r_{1}{ }^{2} r_{2}{ }^{2} p_{0} b}{\left(r_{2}{ }^{4}-r_{1}{ }^{4}\right)\left(r_{2}{ }^{2}-r_{1}{ }^{2}\right)-4 b^{2}{r_{1}}^{2}{r_{2}}^{2}} \times\left[x-\frac{r_{2}{ }^{2}-r_{1}{ }^{2}-b^{2}}{2 b}-\frac{b r_{2}{ }^{2}}{r_{2}{ }^{2}-r_{1}^{2}}\right] .
$$

The value of $\sigma_{z z}=\sigma_{z z}{ }^{\mathrm{I}}+\sigma_{z z}{ }^{\mathrm{II}}$ is shown graphically in Fig. 9 for $r_{1} / r_{2}=b /\left(r_{2}-r_{1}\right)=1 / 2$, in units of the internal pressure, $p_{0}$. Thus, ignoring end effects, the stresses of interest are determined.

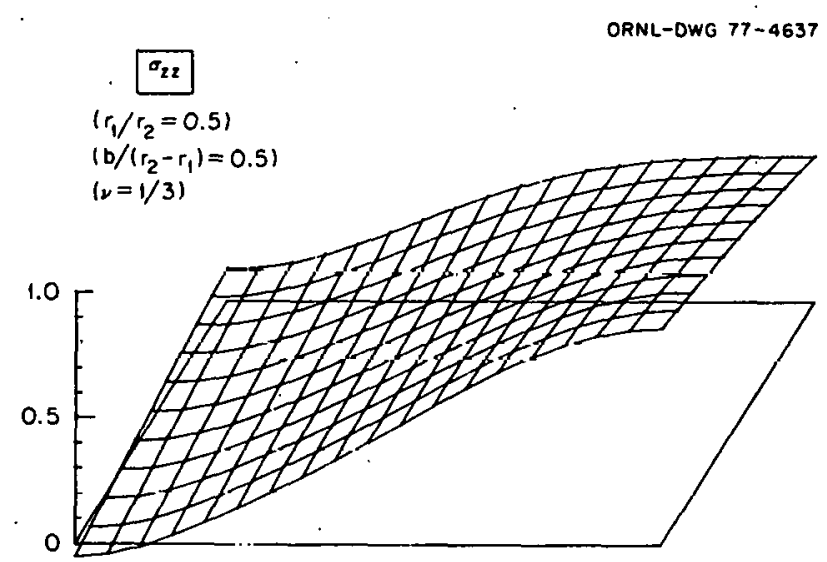

Fig. 9. The value of $a_{3 j}$ over the eccentric tube cross section. In units of $p_{0}$, the internal pressure. 
As in the case of the thin-walled tube in Sect. 3, the bending curvature associated with pressurization may be given for the thick-walled tube. The initial elastic curvature, $1 / R_{0}$, is directly obtainable from $\sigma_{z z}$ II in Eq. (61), since $\sigma_{z z}$ I contributes no axial strain:

$$
\frac{1}{R_{0}}=\frac{p_{0}}{E} \cdot \frac{-4(1-2 \nu) r_{1}^{2} r_{2}^{2} b}{\left(r_{2}^{4}-r_{1}^{4}\right)\left(r_{2}^{2}-r_{1}^{2}\right)-4 b^{2} r_{1}^{2} r_{2}^{2}}
$$

When $r_{1} \approx r_{2}$, the above result reduces to that for the thin-walled pressurized tube, derived earlier in Eq. (18).

\section{APPLICATION OF THE CONSTITUTIVE LAW TO THE PLASTIC DEFORMATION OF PRESSURIZED ECCENTRIC TUBES}

In this section we will describe the plastic behavior of the pressurized eccentric tube. The experiments for which this analysis is applicable are ones in which tubes are pressurized and irradiated and then depressurized. Thus the effect to be studied is some aspect of the plastic deformation occurring during irradiation under internal pressure. A brief analysis will be given for the plastic deformation, driven by the previously defined elastic loading; specifically, the curvature along the length of the tube is described. Also, specimen design criteria will be given, emphasizing the avoidance of yielding during these experiments.

\subsection{Plastic Analysis}

One may begin by writing Hooke's law for the elastic strain in the axial $(z)$ direction of the tube:

$$
\epsilon_{E x}^{e}=\sigma_{B g}-\nu\left(\sigma_{x x}+\sigma_{y y}\right)
$$

The elastic strain, $\epsilon_{z z}{ }^{e}$, may be rewritten as

$$
\epsilon_{z z}^{e}=\epsilon_{z z}{ }^{T O T}-\epsilon_{z z}^{p}
$$

where $\epsilon_{z z}$ TOT is the total strain and $\epsilon_{z z}{ }^{p}$ is the plastic strain at any time after the initial loading. Given the necessary assumption that all planes remain planar, the total axial strain at any point may be described in terms of a uniform axial strain plus a strain component that varies linearly acruss the cruss section (in the $x$ direction; see Fig. 3):

$$
\epsilon_{z z} T O T=\epsilon_{z z}^{0}-\frac{x^{*}}{R}
$$

where $\epsilon_{z z}{ }^{0}$ is the uniform axial strain at any time, $x^{*}\left(=x-x_{0}\right)$ is the position coordinate specified relative to the position of the centroid at $x_{0}$, and $1 / R$ is the instantaneous curvature of the tube. Rewriting Eq. (63) and noting that $\sigma_{x x}+\sigma_{y y}=\sigma_{\eta \eta}+\sigma_{\xi \xi}$ in bipolar coordinates (or $\sigma_{r r}+\sigma_{\theta \theta}$ in the cylindrical coordinates associated with the thin-walled tube),

$$
E\left(\epsilon_{z z}^{0}-\frac{x^{*}}{R}\right)-E \epsilon_{z z}^{p}=\dot{\sigma}_{z z}-\nu\left(\sigma_{\eta \eta}+\sigma_{\xi \xi}\right) .
$$


Here we will introduce the constitutive relation developed earlier for the plastic strain rate [see Eqs. (8), (9), and (10)]. The strain rate component of interest, $\dot{\epsilon}_{z z}{ }^{p}$, is given by

$$
\dot{\epsilon}_{z z}^{p}=f_{0} \frac{1}{3}+f_{2}\left[\sigma_{z z}-\frac{1}{3}\left(\sigma_{z z}+\sigma_{\eta \eta}+\sigma_{\xi \xi}\right)\right] .
$$

The factors $f_{0}$ and $f_{2}$ were specified as functions of time, temperature, neutron flux, dilatation, and hydrostatic pressure. These functions will be assumed to be of a form allowing a separation of the hydrostatic stress dependence in the following way:

$$
\begin{aligned}
& f_{0}=f_{0}{ }^{\prime}\left(i+P \sigma_{H}\right), \\
& f_{2}=f_{2}{ }^{\prime}\left(1+Q \sigma_{H}\right) .
\end{aligned}
$$

As mentioned earlier in Sect. 2, it is consistent with experimental observations to eliminate terms having greater than one-power stress dependence. Thus, we will set $Q=0$ (and in doing so, make the problem considerably more tractable).

Equation (67) may be written as

$$
\dot{\epsilon}_{z z}^{p}=\frac{f_{0}^{\prime \prime}}{3}+a_{z z}\left(\frac{f_{0}^{\prime} P}{9}+\frac{2 f_{2}^{\prime \prime}}{3}\right)-\left(\frac{-f_{0}^{\prime} P}{9}+\frac{f_{2}^{\prime \prime}}{3}\right)\left(\sigma_{\eta \eta}+\sigma_{\xi \xi}\right)
$$

Letting $\psi=f_{0}^{\prime} P / 9+2 f_{2}^{\prime} / 3$ and $\nu^{p}=\left(-f_{0}^{\prime} P / 9+f_{2}^{\prime} / 3\right) / \psi$,

$$
\dot{\epsilon}_{z z}^{p}=\frac{f_{0}^{\prime}}{3}+\psi\left[\sigma_{z z}-\nu^{p}\left(\sigma_{\eta \eta}+\sigma_{\xi \xi}\right)\right]
$$

where $\nu^{p}$ may be considered as a plastic Poisson's ratio.

To obtain the plastic strain called for in Eq. (66), one must make an assumption about the time dependence of the factors $\psi$ and $\nu^{p}$. Here we will assume that average values $\bar{\psi}$ and $\bar{\nu}^{p}$ may be used. (From the data on 316 stainless steel, it appears that the incubation period plus linear time dependence of swelling and the small transient behavior plus linear time dependence of in-reactor creep allow increased validity for this assumption with increased time of irradiation, for $\phi t \widetilde{>} \times 10^{26}$ neutrons $/ \mathrm{m}^{2}$, energy > $0.1 \mathrm{MeV}$ ) Therefore we may write

$$
\epsilon_{z z}^{p}=\dot{\bar{\epsilon}}_{z z}^{p} \times t=\frac{\bar{f}_{0}^{\prime} t}{3}+\bar{\psi} t\left[\bar{\sigma}_{z z}-\bar{\nu}^{p}\left(\bar{\sigma}_{\eta \eta}+\bar{\sigma}_{\xi \xi}\right)\right]
$$

wheıe all quantities having bars above them arc timc-avcragcd.

Substituting $\epsilon_{z z}{ }^{p}$ into Eq. (66) and taking the first moment of each quantity over the area (i.e. $\iint x^{*}$ $d A$ ) ,

$E \iint \epsilon_{z z}{ }^{0} x^{*} d A-\frac{E}{R} \iint x^{* 2} d A-E t \int \frac{\bar{f}_{0}^{\prime}}{3} x^{*} d A-E \bar{\psi} t \iint \bar{\sigma}_{z z} x^{*} d A+E \bar{\psi} t \bar{\nu}^{p} \iint\left(\bar{\sigma}_{\eta \eta}+\bar{\sigma}_{\xi \xi}\right) x^{*} d A$

$$
=\iint \sigma_{z 2} x^{*} d A-v \int\left(\sigma_{n \eta}+\sigma_{\xi \xi}\right) x * d A
$$


The first and third terms on the left disappear, since each represents a constant displacement. From the condition of mechanical equilibrium for small strains, it follows that

$$
\iint \sigma_{z z} x^{*} d A=\iint \bar{\sigma}_{z z} x^{*} d A=\frac{\pi r_{1}{ }^{2} r_{2}{ }^{2} p_{0} b}{r_{2}{ }^{2}-r_{1}{ }^{2}} \text {. }
$$

(For the thin-walled tube, the term on the right is $\pi r^{2} p_{0} \delta \gamma$.) Thus, noting also that $\iint x^{*} d A$ is the moment of inertia, $I$, given earlier in Eq. (59),

$$
-\frac{1}{R}=\left(\frac{\bar{\psi} t}{I}+\frac{1}{\overline{E I}}\right)\left(\frac{\pi r_{1}^{2} r_{2}^{2} b p_{0}}{r_{2}^{2}-r_{1}^{2}}\right)-\frac{\bar{\psi} t \bar{\nu}}{I} \iint\left(\bar{\sigma}_{\eta \eta}+\bar{\sigma}_{\xi \xi}\right) x^{*} d A-\frac{\nu}{E I} \iint\left(\sigma_{\eta \eta}+\sigma_{\xi \xi}\right) x^{*} d A .
$$

The further assumption may be made that, for small strains, $\iint\left(\sigma_{\eta \eta}+\sigma_{\xi \xi}\right) x * d A$ is constant and

$$
\iint\left(\sigma_{\eta \eta}+\sigma_{\xi \xi}\right) x^{*} d A=\iint\left(\bar{\sigma}_{\eta \eta}+\bar{\sigma}_{\xi \xi}\right) x^{*} d A=\frac{2 \pi r_{1}{ }^{2} r_{2}{ }^{2} p_{0} b}{{r_{2}{ }^{2}-r_{1}{ }^{2}}}
$$

By making this substitution and by substituting $1 / R_{0}$, the initial elastic curvature, into Eq. (74),

$$
-\frac{1}{R}=\left(\frac{\bar{\psi} t E\left(1-2 \bar{\nu}^{p}\right)}{1-2 \nu}+1\right)\left(-\frac{1}{R_{0}}\right)
$$

where

$$
\frac{1}{R_{0}}=-\frac{(1-2 \nu) r_{1}^{2} r_{2}^{2} p_{0} b}{F I\left(r_{2}^{2}-r_{1}^{2}\right)}
$$

(The value of $1 / R_{0}$ is $-(1-2 \nu) p_{0} \delta \ddot{\gamma} /\left(2 E \gamma_{0}{ }^{2}\right)$ for the thin-walled tube.)

Again, we invoke the reguirement that strains be small, and we assume that upnn depressurizatinn a reverse curvature will be observed that is identical in magnitude to the initial elastic curvature, $1 / R_{\mathbf{0}}$. Thus, the residual curvature $1 / R_{r}$ after depressurization is given by

$$
\frac{1}{K_{r}}=E t \bar{\psi}\left(\frac{1-2 \bar{\nu}^{p}}{1-2 \nu}\right) \frac{1}{R_{0}} .
$$

Using the fảct that

$$
1-2 \bar{\nu}^{p}=\frac{\overline{f_{0}^{\prime} P}}{3 \psi}
$$

Eq. (18) may be rewritten

$$
\frac{1}{R_{r}}=p_{0}\left(\frac{\bar{f}_{0}{ }^{\prime} t}{3}\right) P \cdot\left(\frac{4 b r_{1}{ }^{2} r_{2}{ }^{2}}{\left(r_{2}{ }^{4}-r_{1}{ }^{4}\right)\left(r_{2}{ }^{2}-r_{1}{ }^{2}\right)-4 b^{2} r_{1}{ }^{2} r_{2}{ }^{2}}\right) .
$$


When $\bar{\nu}^{p}=1 / 2$ or, equivalently, when $P=0$, the plastic curvature disappears; that is, linearly stress-dependent deviatoric strain will not cause a change in curvature. Therefore, we may describe the plastic deformation occurring during irradiation in terms of the pressure, the linear stress-free swelling, a material constant that relates the swelling rate to the hydrostatic pressure, and a geometric factor.

\subsection{Point of Maximum Shear Stress}

Before an estimate may be made of the residual curvature after irradiation, the maximum internal pressure that may be applied to the tube must be known. The criterion here for the maximum pressure is that pressure which, if exceeded, will cause yielding at some point in the tube. In this section the maximum shear stress in the tube will be estimated for a given internal pressure.

We will begin by examining the stresses on the internal surface at $\xi=\xi_{1}$. The stresses $\sigma_{\xi \xi}\left(\xi_{1}\right)$ and $\sigma_{\eta \eta}$ $\left(\xi_{1}\right)$ are, respectively,

$$
\begin{aligned}
& \sigma_{\xi \xi}\left(\xi_{1}\right)=-p_{0} \\
& \sigma_{\eta \eta}\left(\xi_{1}\right)=-p_{0}+2 p_{0}\left(\frac{r_{2}{ }^{2}}{{r_{1}}^{2}+r_{2}{ }^{2}}\right)\left[\frac{\left(r_{2}{ }^{2}-b^{2}\right)^{2}-r_{1}{ }^{2}\left(r_{1}+2 b \cos \eta\right)^{2}}{\left(r_{2}{ }^{2}-r_{1}{ }^{2}-b^{2}\right)^{2}-4 b^{2} r_{1}{ }^{2}}\right] .
\end{aligned}
$$

It may be shown ${ }^{6}$ that $\sigma_{\eta \eta}\left(\xi_{1}\right)$ is always positive and that minimum value for $\sigma_{\eta \eta}\left(\xi_{1}\right)$ occurs at the thickest point of the tube or when $\eta=0$ (see Figs. 3,7). The value of $\sigma_{\eta \eta}\left(\xi_{1}, 0\right)$ is given in Table 1 for the case where $r_{1} / r_{2}=b /\left(r_{2}-r_{1}\right)=1 / 2$. The maximum value of $\sigma_{\eta \eta}\left(\xi_{1}\right)$ on the internal surface occurs at $\eta=\pi$, where the tube is thinnest, when $b<r_{1} / 2$. However, when $b>r_{1} / 2$, the maximum value of $\sigma_{\eta \eta}\left(\xi_{1}\right)$ occurs at the two oblique points where $\cos \eta=-r_{1} / 2 b$. The value of $\sigma_{z z}$ may be obtained from

$$
\begin{aligned}
\sigma_{z z}\left(\xi_{1}\right)=\frac{-4(1-2 v) p_{0} r_{1}{ }^{2} r_{2}{ }^{2} b}{\left(r_{2}{ }^{4}-r_{1}{ }^{4}\right)\left(r_{2}{ }^{2}-r_{1}{ }^{2}\right)-4 r_{1}{ }^{2} r_{2}{ }^{2} b^{2}} \\
\times\left[x-\frac{r_{2}{ }^{2}-r_{1}{ }^{2}-b^{2}}{2 b}+\frac{b r_{2}{ }^{2}}{r_{2}{ }^{2}-r_{1}{ }^{2}}\right]+\nu\left[\sigma_{\eta \eta}\left(\xi_{1}\right)+\sigma_{\xi \xi}\left(\xi_{1}\right)\right],
\end{aligned}
$$

Table 1. Calculated stresses fur the pressurized eccentric tube

The values are given for the case where $r_{1} / r_{2}=b /\left(r_{2}-r_{1}\right)=1 / 2$ and where $\nu=1 / 3$. The values shown in parentheses are those for the tubes having $r_{1} / r_{2}=0.76$ and $b /\left(r_{2}-r_{1}\right)=0.50$.

\begin{tabular}{lccc}
\hline & $\sigma_{\eta \eta}$ & $\sigma_{z z}$ & $\sigma_{\xi \xi}$ \\
\hline$\xi=\xi_{1}, \eta=0$ & $1.45 p_{0}$ & $0.13 p_{0}$ & $-p_{0}$ \\
$\xi=\xi_{2}, \eta=0$ & $\left(2.71 p_{0}\right)$ & $\left(0.40 p_{0}\right)$ & $\left(-p_{0}\right)$ \\
& $0.21 p_{0}$ & $-0.05 p_{0}$ & 0 \\
$\xi=\xi_{1}, \eta=\pi$ & $\left(1.39 p_{0}\right)$ & $\left(0.16 p_{0}\right)$ & $(0)$ \\
& $2.43 p_{0}$ & $0.59 p_{0}$ & $-p_{0}$ \\
$\xi=\xi_{2}, \eta=\pi$ & $\left(6.64 p_{0}\right)$ & $\left(2.26 p_{0}\right)$ & $\left(-p_{0}\right)$ \\
& $2.19 p_{0}$ & $0.87 p_{0}$ & 0 \\
& $\left(6.59 p_{0}\right)$ & $\left(2.62 p_{0}\right)$ & $(0)$ \\
\hline
\end{tabular}


where

$$
x=\frac{\left(r_{2}^{2}-r_{1}^{2}-b^{2}\right)^{2}-4 b^{2} r_{1}^{2}}{2 b\left(r_{2}{ }^{2}-r_{1}{ }^{2}-b^{2}\right)-4 b^{2} r \cos \eta} .
$$

Assuming a Poisson's ratio of $1 / 3$, the values of $\sigma_{z z}\left(\xi_{1}, 0\right)$ and $\sigma_{z z}\left(\xi_{1}, \pi\right)$ may be calculated; these values are shown in Table 1. For the points at $\eta=\pi, \sigma_{\eta \eta}\left(\xi_{1}\right)>\sigma_{z z}\left(\xi_{1}\right)>\sigma_{\xi \xi}\left(\xi_{1}\right)$. The same order applies to these stresses on the external surface $\left(\xi=\xi_{2}\right)$. The stresses at $\xi=\xi_{2}$ are given by the following:

$$
\begin{gathered}
\sigma_{\xi \xi}\left(\xi_{2}\right)=0, \\
\sigma_{\eta \eta}\left(\xi_{2}\right)=\frac{2 p_{0} r_{1}{ }^{2}}{r_{2}{ }^{2}+r_{1}{ }^{2}}\left[\frac{r_{2}{ }^{3}\left(r_{2}-2 b c 0 s \eta\right)^{2}-\left(r_{1}{ }^{2}-b^{2}\right)^{2}}{\left(r_{2}{ }^{2}-r_{1}{ }^{2}-b^{2}\right)^{2}-4 b^{2} r_{1}{ }^{2}}\right], \\
\sigma_{z z}\left(\xi_{2}\right)=\frac{-4(1-2 \nu) p_{0} r_{1}{ }^{2} r_{2}{ }^{2} b}{\left(r_{2}{ }^{4}-r_{1}{ }^{4}\right)\left(r_{2}{ }^{2}-r_{1}{ }^{2}\right)-4 r_{1}{ }^{2} r_{2}{ }^{2} b^{2}}\left[\begin{array}{r}
\left.2 b-\frac{r_{2}{ }^{2}-r_{1}{ }^{2}-b^{2}}{2 b}+\frac{b r_{2}{ }^{2}}{r_{2}{ }^{2}-r_{1}}\right] \\
\quad+\nu\left[\sigma_{\eta \eta}\left(\xi_{2}\right)+\sigma_{\xi \xi}\left(\xi_{2}\right)\right]
\end{array}\right.
\end{gathered}
$$

where

$$
x=\frac{\left(r_{2}^{2}-r_{1}^{2}+b^{2}\right)^{2}-4 b^{2} r_{2}^{2}}{2 b\left(r_{2}^{2}-r_{1}^{2}+b^{2}\right)-4 b^{2} r_{2} \cos \eta} .
$$

The values of these stresses are also listed in Table 1.

A detailed analysis of the maximum stress for all values of the geometric parameters is beyond the scope of this work. For the two geometries chosen, namely for $r_{1} / r_{2}=0.5$ and $r_{1} / r_{2}=0.76$ with $b /\left(r_{2}-r_{1}\right)=$ $1 / 2$, Figs. 6-13 show graphically that the maximum value of stress is that of $\sigma_{\eta \eta}$ at $\eta=\pi, \xi=\xi_{1}$, that is, the interior surface at the thinnest point. As was mentioned earlier, this is not the case for all geometries. Furthermore, for the cases cited, the maximurn stress difference, $\sigma_{\eta \eta}-\sigma_{\xi \xi}$, occurs at the same point. Thus, the maximum shear stress, $\tau_{\max }$, is given by

$$
\begin{aligned}
& \tau_{\max }=\frac{1}{2}\left[n_{\eta \eta \eta}\left(\xi_{1}, \pi\right)=\pi_{\xi \xi}\left(\xi_{1}, \pi\right)\right], \\
& \tau_{\max }=\frac{P_{0} r_{2}^{2}}{r_{1}^{2}+r_{2}^{2}}\left(\frac{r_{2}^{2}-b^{2}-2 r_{1} b-r_{1}^{2}}{r_{2}^{2}-b^{2}-2 r_{1} b-r_{1}^{2}}\right) .
\end{aligned}
$$

Assuming a Tresca yielding criterion, that is, when the maximum shear stress equals one-half of the yield stiess $v_{y}$, yielding occurs when

$$
\sigma_{y}=\frac{2 p_{0} r_{2}{ }^{2}}{{r_{1}}^{2}+r_{2}{ }^{2}}\left(\frac{r_{2}{ }^{2}-b^{2}-2 r_{1} b+r_{1}{ }^{2}}{r_{2}{ }^{2}-b^{2}-2 r_{1} b-r_{1}{ }^{2}}\right) .
$$




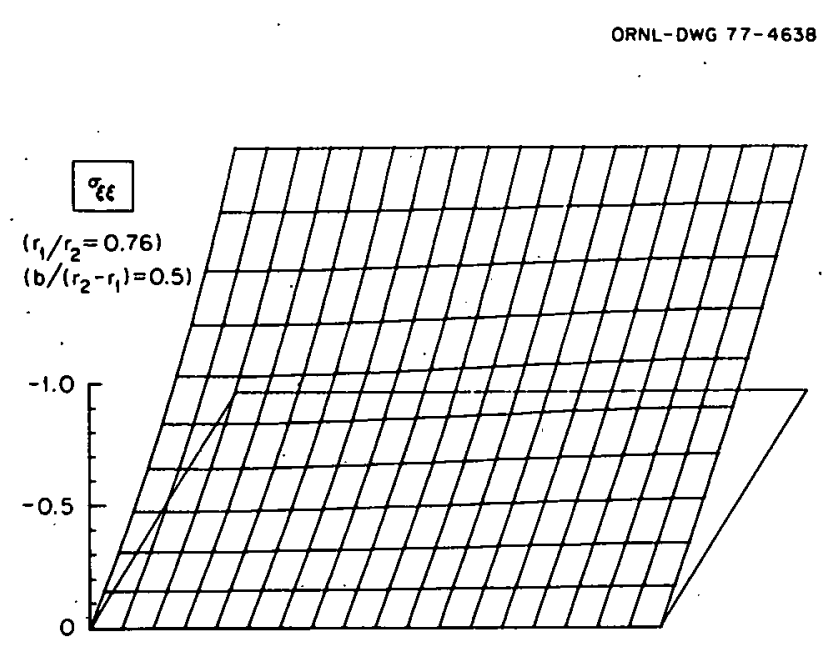

Fig. 10. The value of $\sigma_{\xi \xi}$ over the eccentric tube cross section. In units of $p_{0}$, the internal pressure.

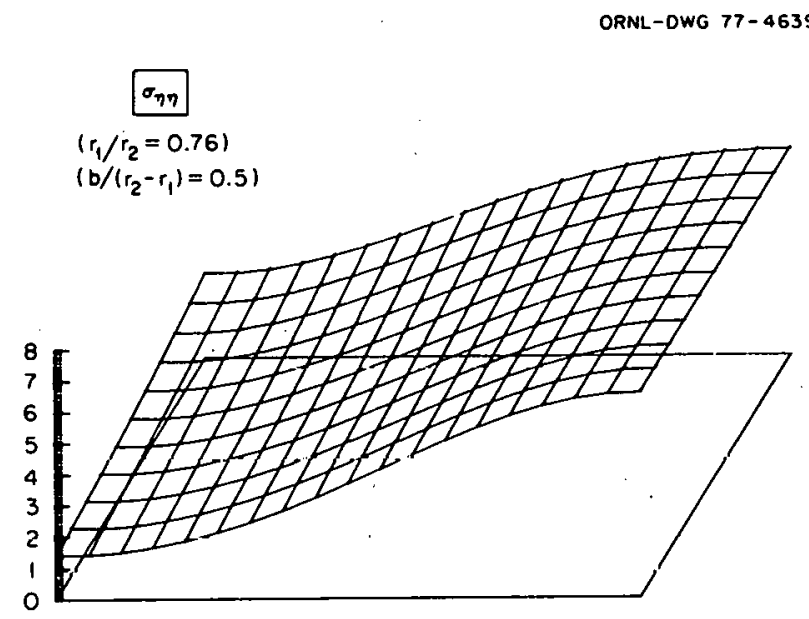

Fig. 11. The value of $\sigma_{\eta \eta}$ over the eccentric tube cross section. In units of $p_{0}$, the internal pressure.

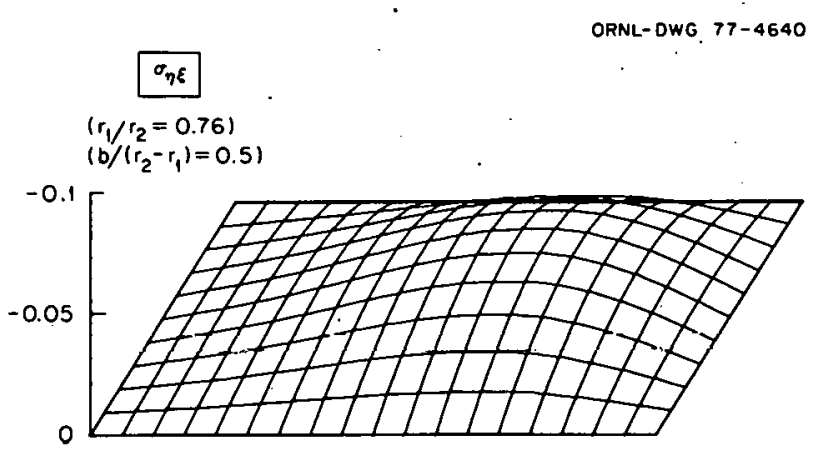

Fig. 12. The value of $\sigma_{\eta \xi}$ over the eccentric tube cross section. In units of $p_{0}$, the internal pressure. 


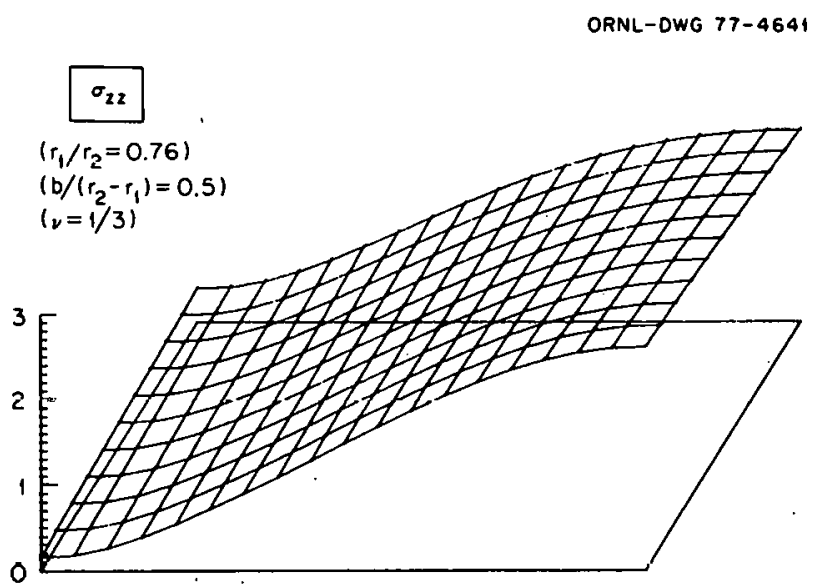

Fig. 13. The value of $\sigma_{z z}$ over the eccentric tube cross section. In units of $\dot{p}_{0}$, the internal pressure.

For a given yield stress, the maximum curvature that may be expected (for the geometries chosen in Table 1) is found using Eq. (80):

$$
\begin{aligned}
\left.\frac{1}{R_{r}}\right)_{\max }=\left[\frac{\sigma_{y}\left(r_{1}{ }^{2}+r_{2}{ }^{2}\right)}{2 r_{2}{ }^{2}} \frac{r_{2}{ }^{2}-b^{2}-2 b r_{1}-r_{1}{ }^{2}}{r_{2}{ }^{2}-b^{2}-2 b r_{1}+r_{1}{ }^{2}}\right] \\
\times \frac{\bar{f}_{0}{ }^{\prime} t}{3} P\left[\frac{4 b r_{1}{ }^{2} r_{2}{ }^{2}}{\left(r_{2}{ }^{4}-r_{1}{ }^{4}\right)\left(r_{2}{ }^{2}-r_{1}{ }^{2}\right)-4 b^{2} r_{1}{ }^{2} r_{2}{ }^{2}}\right] .
\end{aligned}
$$

And, letting $S=\dddot{f}_{0}^{\prime} \cdot t$, the volumetric swelling of the material,

$$
\left.\frac{1}{R_{r}}\right)_{\max }=\sigma_{y} \frac{S}{3} P K\left(r_{1}, r_{2}, h\right)
$$

where

$K\left(r_{1}, r_{3}, h\right)=\frac{2 b r_{1}{ }^{2}\left(r_{1}{ }^{2}+r_{2}{ }^{2}\right)\left[r_{2}{ }^{2}-\left(r_{1}+b\right)^{2}\right]}{\left\lfloor r_{2}{ }^{2}-b^{2}-2 b r_{1}+r_{1}{ }^{2}\right\rfloor\left\lfloor\left(r_{2}{ }^{4}-r_{1}^{4}\right)\left(r_{2}{ }^{2}-r_{1}{ }^{2}\right)-4 b^{2} r_{1}^{2} r_{2}{ }^{2}\right\rfloor}$.

and $P$ is the coefficient relating swelling to hydrostatic stress (see Eq. 68).

\subsection{Experimental Procedure}

Eccentric tubes were prepared to allow determination of the constant $P$, relating swelling to the hydrostatic stress. The material chosen was a high-swelling, rather pure heat of $316 \mathrm{~L}$ stainless steel. The 
composition of the alloy is listed below, and the swelling behavior for this material irradiated in EBR-II is shown in Fig. 14.

Composition of the $316 \mathrm{~L}$ stainless steel used in the pressurized eccentric tubes

\begin{tabular}{cccccccc}
\hline $\mathrm{Fe}$ & $\mathrm{Cr}$ & $\mathrm{Ni}$ & $\mathrm{Mo}$ & $\mathrm{Mn}$ & $\mathrm{C}$ & $\mathrm{Si}$ & $\mathrm{S}$ \\
\hline Balance & 17.5 & 14.4 & 2.8 & 0.1 & 0.006 & 0.02 & 0.002 \\
\hline
\end{tabular}

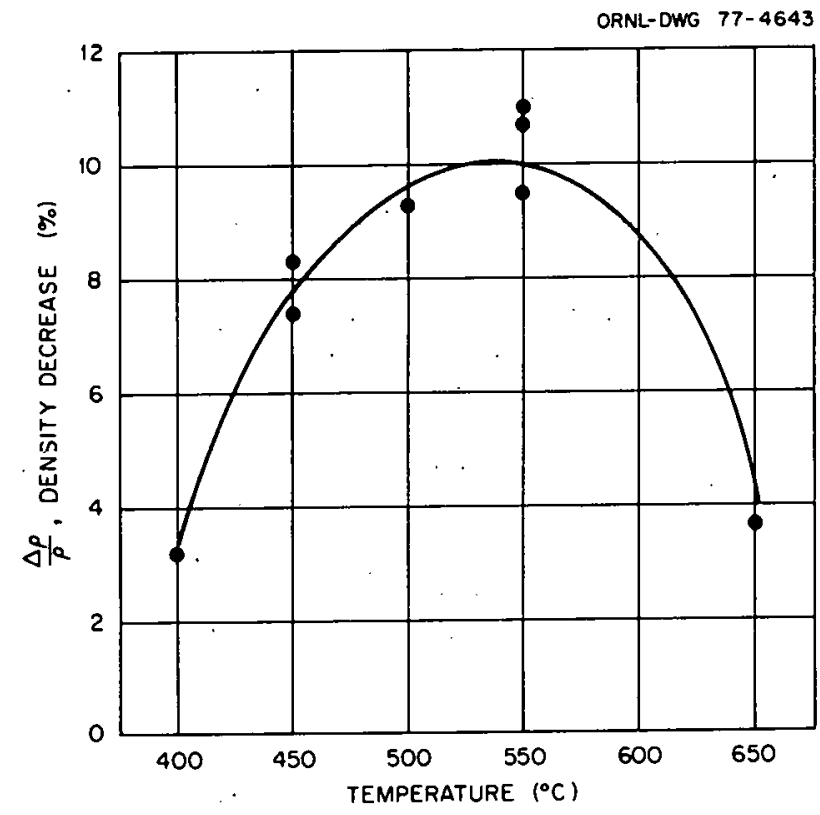

Fig. 14. Temperature dependence of neutron-irradiation-induced density decrease in high-purity 316 stainless steel for a fiuence of $2 \times 10^{26}$ neutrons $/ \mathrm{m}^{2}(E>0.1 \mathrm{MeV})$.

The dimensions of the tube, along with the geometry of the end caps, which were electron-beam-welded to the tubes, are shown in Fig. 15.

The tubes and end caps were machined from $25 \%$ cold-swaged material. The end caps were then welded in place. One end cap had a 0.005 -in. $(130-\mu \mathrm{m})$ hole into which was inserted a 0.0045 -in. $(110-\mu \mathrm{m})$ wire made from 312 stainless steel. This alloy was chosen to improve the laser welding characteristics of the end caps. The tubes were then annealed at $800^{\circ} \mathrm{C}$ for $1 \mathrm{hr}$ and subsequently pressurized and laser-welded at 'HEDL by M. Paxton.

These tubes were included in an ORNL experimental assembly placed in EBR-II at the time of this writing. Ten tubes will be irradiated during 1976-1977 to a fluence of about $4 \times 10^{26}$ neutrons $/ \mathrm{m}^{2}, E>$ $0.1 \mathrm{MeV}$. Five will be irradiated at $525^{\circ} \mathrm{C}$ and five at $575^{\circ} \mathrm{C}$. The expected stress-free volumetric swelling at both temperatures is about $23 \%$, assuming an incubation fluence of $5 \times 10^{2 \mathrm{~s}}$ neutrons $/ \mathrm{m}^{2}$ and a constant swelling rate. ${ }^{10}$

The pressures in each of the tubes are listed in Table 2, along with the irradiation temperature and expected maximum stress. For control purposes, one from each set of five tubes is a concentric tube having

10. E. E. Bloom, unpublished data. 


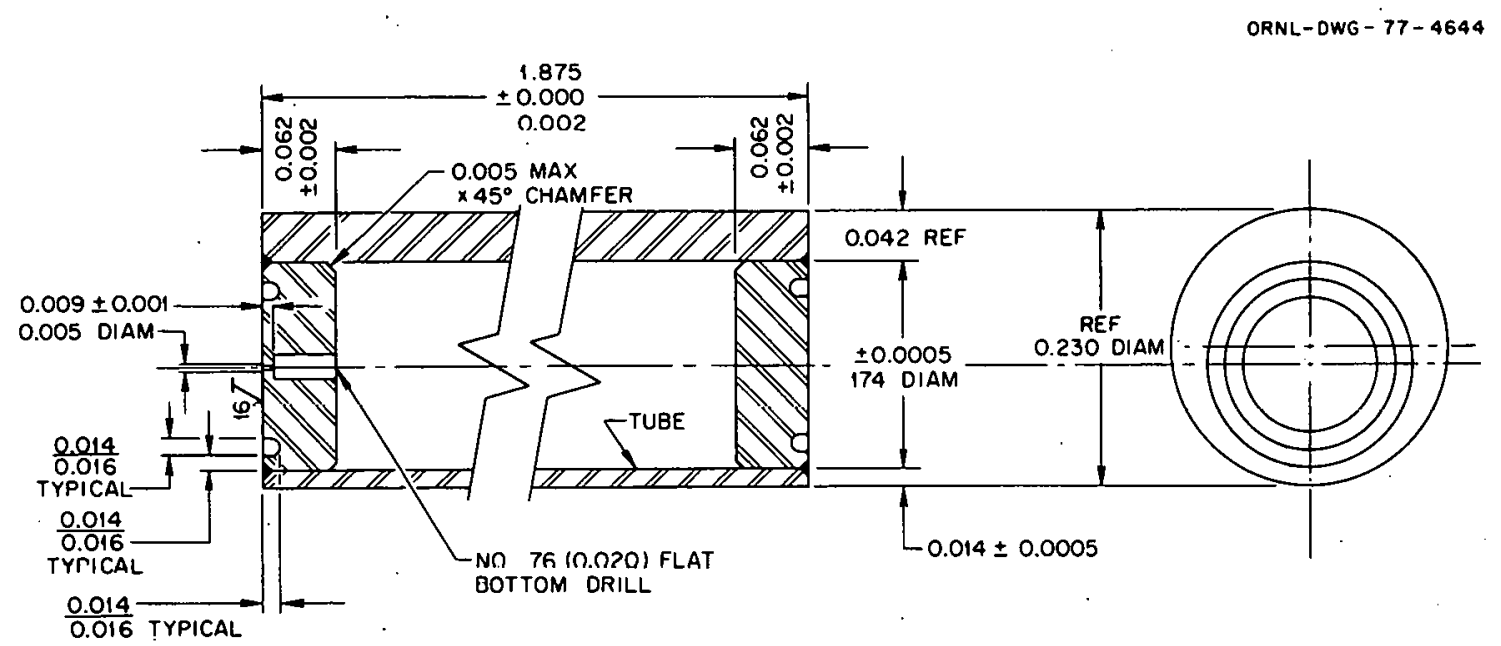

Fig. 15. The experimental pressurized tube geometry.

Table 2. Experimental conditions for the pressurized eccentric tubes

\begin{tabular}{lcccc}
\hline Tube & $\begin{array}{c}\text { Fill } \\
\text { pressure } \\
\text { (psia) }\end{array}$ & $\begin{array}{c}\text { Operating } \\
\text { pressure } \\
\text { (psia) }\end{array}$ & $\begin{array}{c}\text { Maximum } \\
\text { shear stress } \\
(\mathrm{psi})\end{array}$ & $\begin{array}{c}\text { Operating } \\
\text { temperature } \\
\left({ }^{\circ} \mathrm{C}\right)\end{array}$ \\
\hline $\mathrm{AA}^{a}$ & 574 & 1661 & 3700 & 575 \\
$\mathrm{BB}$ & 574 & 1661 & 6200 & 575 \\
$\mathrm{CC}$ & 574 & 1661 & 6200 & 575 \\
$\mathrm{DD}$ & 293 & 848 & 3100 & 575 \\
$\mathrm{EE}$ & 8 & & & 575 \\
$\mathrm{FF}^{a}$ & 608 & 1656 & 3700 & 525 \\
$\mathrm{GG}$ & 608 & 1656 & 6200 & 525 \\
$\mathrm{HH}$ & 608 & 1656 & 6200 & 525 \\
$\mathrm{JI}$ & 0 & 0 & & 525 \\
$\mathrm{KK}$ & 8 & 0 & & 525 \\
\hline
\end{tabular}

${ }^{a}$ Denotes concentric tube.

${ }^{b}$ Denotes leaking tube that was evacuated.

a uniform wall thickness of 0.028 in. $(0.71 \mathrm{~mm})$ and an outer diameter of $0.230 \mathrm{in} .(5.84 \mathrm{~mm})$. One of the five tubes is not under pressure, also as a control. Two tubes of each set were pressurized to what was felt to be a safe maximum, thereby avoiding ylelding at the uperating temperature. The yield stress for our material was assumed to be that for solution-annealed 316 stainless steel, which has a minimum expected yield strength at $575^{\circ} \mathrm{C}$ of $17,000 \mathrm{psi}(117 \mathrm{MPa}) .^{11}$ The fifth tube of each set was pressurized to one-half of the safe limit (assumed to be 12,500 psi). Compensation was made for the hydrostatic pressure in the reactor of $32.7 \mathrm{psi}(0.23 \mathrm{MPa})$ and $36.7 \mathrm{psi}(0.26 \mathrm{MPa})$ for the lubes at 525 and $575^{\circ} \mathrm{C}$ respectively.

Once the tubes are removed from the reactor, the deflection from a uniformly straight tube will be measured. The deflection, $\delta$, shown in Fig. 16, and the tube length, $l$, equal to about $1.5 \mathrm{in}$. (38 $\mathrm{mm})$ for measurement purposes, are related to the residual curvature by

$$
\delta=R_{r}-\left(R_{r}^{2}-l^{2}\right) ! / 2
$$

11. Hanford Engineering Development Laboratory, Nuclear Systems Materials Handbook, vol. 1, Design Data, TID-26666, Property Code 2102, p.1, Richland, Wash. (continually updated). 


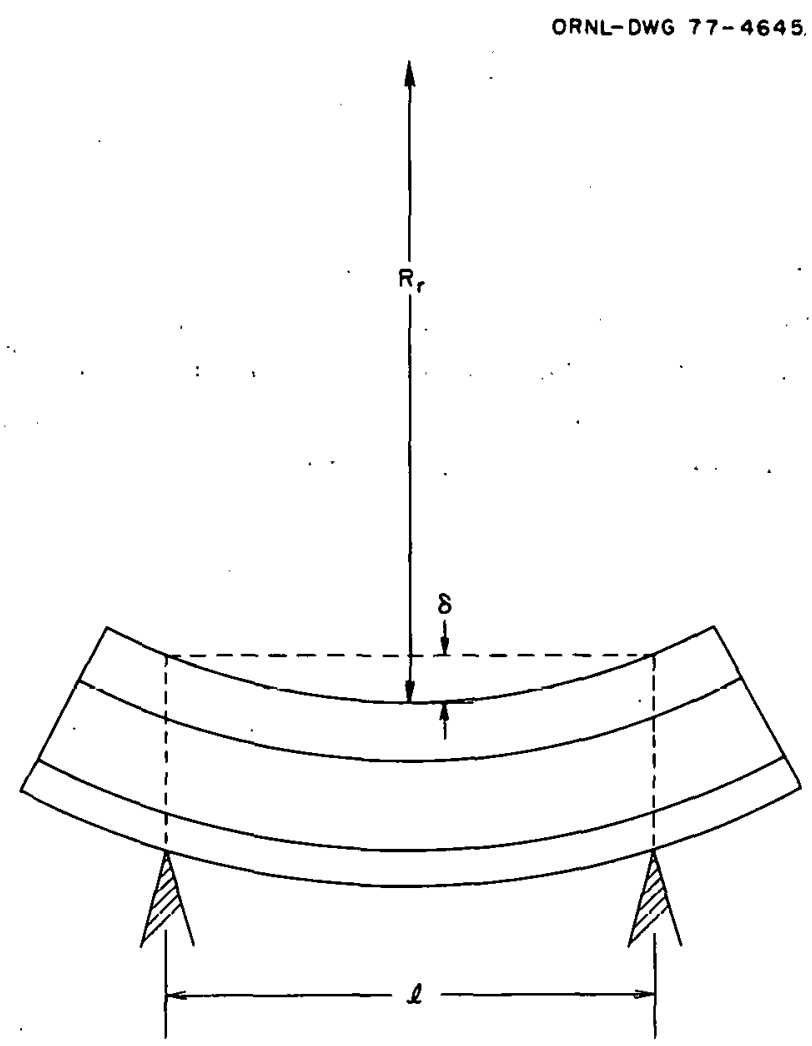

Fig. 16. The deflection $\delta$ to be measured after irradiation and depressurization.

By setting the volumetric swelling to $S=0.23$ and the pressure to $p_{0}=1624 \mathrm{psi}(11.2 \mathrm{MPa})$ and by using the experimental geometry given in Fig. 15, one may find the expected deflection by combining Eqs. (80) and (95):

$$
\delta=8.41 \times 10^{-4} P^{-1}-\left[\left(8.41 \times 1 U^{-4} \mu^{-1}\right)^{2}-2.25\right]^{1 / 2} .
$$

For a value of $P=5 \times 10^{-7} \mathrm{psi}^{-1}$ (which corresponds to an increase in the rate of swelling by $0.05 \%$ per $1000 \mathrm{psi}$ ), the value of $\delta$ is measurable:

$$
\delta\left(P=5 \times 10^{-7}{ }_{\mathrm{isi}}^{-1}\right)=6.9 \times 10^{-4} \mathrm{in} .
$$

The resolution for the optical measurement of the deflection should be at least $0.0001 \mathrm{in}$., thereby allowing a measurement of $P$ down to a value of about $10^{-7} \mathrm{psi}^{-1}$. Below this value $P$ becomes a matter of academic importance rather than a matter at all critical to rcactor design.

\section{SUMMARY}

In the preceding sections a constitutive law for deformation of materials being neutron-irradiated was applied to the pressurized eccentric tube. It was shown for the linear stress dependence chosen that, if the hydrostatic stress affects the dilational strain (swelling, in this case), a plastic bowing of the tube will 
develop. Upon depressurization the curvature of the tube may be used to determine the value of the coefficient $P$ that relates hydrostatic stress to swelling:

$$
\frac{1}{R_{r}}=p_{0} \frac{S}{3} P g\left(r_{1}, r_{2}, b\right)
$$

where $1 / R_{r}$ is the residual curvature after depressurization, $p_{0}$ is the internal pressure, $S$ is the volumetric swelling, $g\left(r_{1}, r_{2}, b\right)$ is a geometric constant [see Eq. (80)]. Other deformation modes having hydrostatic : stress-dependent dilatation associated with them may be tested using this technique. For example, the onset of tertiary creep could be monitored using pressurized eccentric tubes. 
ORNL/TM-5780

\section{INTERNAL DISTRIBUTION}

1-2. Central Research Library

3-4. Document Reference Section

5-14. Laboratory Records Department

15. Laboratory Records, ORNL RC

16. ORNL Patent Office

17-19. Technical Publications Department

20. G. M. Adamson

21. D. S. Billington

22. C. R. Brinkman

23. W. A. Coghlan

24. F. L. Culler

-25. J. E. Cunningham

26. W. L. Greenstreet

27. R. G. Donnelly

28. K. Farrell

29. J.S. Faulkner

30. W. O. Harms

31-33. M. R. Hill

34. L. H. Jenkins

35. P. R. Kasten

36. A. L. Lotts

37. L. K. Mansur
38. C. J. McHargue

39. P. Patriarca

40. C. E. Pugh

41-50. T. C. Reiley

51. D. N. Robinson

52. J. L. Scott.

53. G. M. Slaughter

54. J. O. Stiegler

55. D. B. Trauger.

56. J. R. Weir, Jr.

57. F. W. Wiffen

58. M. K. Wilkinson

59. M. H. Yoo

60. F. W. Young, Jr.

61. A. Zucker

62. J. H Frye, Jr. (consultant)

63. P. M. Brister (consultant)

64. John Moteff (consultant)

65. Hayne Palmour III (consultant)

66. J.W. Prados (consultant)

67. N. E. Promisel (consultant)

68. D. F. Stein (consultant)

\section{EXTERNAL DISTRIBUTION}

69. W. K. Applcby, G.E. Company, 310 DeGuigne Drive, Sunnyvale, C $\Lambda 94086$

70. D. M. Barnett, Dept. of Materials Science and Engineering, Stanford University, Stanford, CA 94305

71. J. W. Bennett, Division of Reactor Development and Demonstration, ERDA, Washington, DC 20545

72. M. L. Bleiberg, Advanced Réactors Division, Westinghouse Electric Corp., P.O. Box 158, Madison, PA 15663

73. E. E. Bloom, Electric Power Research Institute, 3412 Hillsview Avenue, Palo Alto, CA 94304

74. A. Bolton, Advanced Reactors Division, Westinghouse Electric Corp., P.O. Box 158, Madison, PA 15663

75. J. L. Brimhall, Battelle Pacific Northwest Laboratory, P.O. Box 999, Richland, WA 99352

76. R. Bullough, AERE Harwell, Didcot, Oxon., England

77. Chairman, Department of Applied"Sciences, Brookhaven National Laboratory, Upton, NY 11973

78. R. J. DiMelfi, Materials Science Division, Argonne National Laboratory, Argonne, IL 60439

79. Director, Center for Radiation Research, National Bureau of Standards, Room C-225, Washingtón, DC 20234 
80. Director, Research and Technical Support Division, ERDA, Oak Ridge, TN 37830

81. K. Ehrlich, Institute for Material UND Festkorperforschung Kernforschungsrentrum Karlsruhe, 75 Karlsruhe, W. Germany

82-108. ERDA Technical Information Center, Office of Information Services, P.O. Box 62, Oak Ridge, TN 37830

109. B. L. Eyre, AERE Harwell, Didcot, Oxon., England

110. P. Flynn, EBR-II Project, Argonne National Laboratory, Idaho Falls, ID 83401

111. B. T. Frost, Materials Science Division, Argonne National Laboratory, Argonne, IL 60439

112. F. A. Garner, Hanford Engineering Development Laboratory, P.O. Box 1970, Richland, WA 99352

113. M. Hall, Materials Science Division, Argonne National Laboratory, Argonne, IL 60439

114. S. D. Harkness, Materials Science Division, Argonne National Laboratory, Argonne, IL 60439

115. E. W. Hart, Dept. of Materials Science and Engineering, Cornell University, Ithaca, NY 14853

116. J. J. Holmes, Hanford Engineering Development Laboratory, P.O. Box 1970, Richland, WA 99352

117. L. C. Ianniello, Division of Physical Research, ERDA, Washington, DC 20545

118. W. G. Johnston, G.E. Research and Development Center, P.O. Box 8, Schenectady, NY 12301

119. U. F. Kocks, Materials Science Division, Argonne National Laboratory, Argonne, JL 60439

120. D. Kramer, Atomics International, Component Engineering and Technology Division, North American Rockwell, 8900 DeSoto Avenue, Canoga Park, CA 91304

121. E. Krempl, Dept. of Mechanical Engineering, Rensselear Polytechnic Institute, Troy, NY 12180.

122. C-Y. Li, Dept. of Materials Science and Engineering, Cornell University, Ithaca, NY 14853

123. Librarian, AERE Harwell, Didcot, Oxon., England

124. R. P. Marshall, Battelle Pacific Northwest Laboratory, P.O. Box 999, Richland, WA 99352

125. R. S. Nelson, AERE Harwell, Didcot, Oxon., England

126. F. A. Nichols, Materials Science Division, Argonne National Laboratory, Argonne, IL 60439

127. W. D. Nix, Dept. of Materials Science and Engineering, Stanford University, Stanford, CA 94305

128. T. E. Onat, Engineering and Applied Science, Yale University, New Haven, CT 06520

129. W. Pennell, Advanced Reactors Division, Westinghouse Electric Corp., P.O. Box 158, Madison, PA 15663

130. T. C. Reuther, Division of Magnetic Fusion Energy, ERDA, Washington, DC 20545

131. J. R. Rice, Division of Engineering, Brown University, Providence, RI 02912

132. W. Schilling, Institut für Festkorperforschung der Kernforschungsanlage Jülich, Jülich, W. Germany

133. F. Smidt, U.S. Naval Research Laboratory, Code 6390, Washington, DC 20234

134. L. Steele, U.S. Naval Research Laboratory, Code 6390, Washington, DC 20234

135. D. K. Stevens, Division of Physical Research, ERDA, Washington, DC 20545

136. J. L. Straalsund, Hanford Engineering Development Laboratory, P.O. Box 1970, Richland, WA จ७. 35 ?

137. J. Swearengen, Division 5847, Sandia Laboratories, Albuquerque, NM 87115

138. H. Ulmaier, Institut fur Festkorperforschung der Kernforschungsanlage Jülich, Jülich, W. Germany

139. L. C. Walters, EBR-II Project, Argonne National Laboratory, Idaho Falls, ID 83401

140. R. J. Wasilewski, Division of Materials Research, National 3rienile Funindaliun, Washinglun, DC 20550

141. M. S. Wechsler, Ames Research Laboratory, Iowa State University, Ames, IA 50010

142. R. W. Weeks, Materials Science Division, Argonne National Laboratory, Argonne, IL 60439

143. J. Weertman, Dept. of Materials Science, Northwestern University, Evanston, IL 60201

144. G. Wempner, Georgia Institute of Technology, Atlanta, GA

145. G. L. Wire, Hanford Engineering Development Laboratory, P. O. Box 1970, Richland, WA 99352.

146. S. Wolf, Division of Physical Research, ERDA, Washington, DC 20545

147-156. W. G. Wolfer, Dept. of Nuclear Engineering, University of Wisconsin, Madison, WI 53706

157. K. M. Zwilsky, Division of Magnetic Fusion Energy, ERDA, Washington, DC 20545 